\title{
Growth and Interaction of Normal Faults and Fault Network Evolution in Rifts: Insights from Three Dimensional Discrete Element Modelling
}

DOI:

10.1144/SP439.23

\section{Document Version}

Accepted author manuscript

Link to publication record in Manchester Research Explorer

Citation for published version (APA):

Finch, E., \& Gawthorpe, R. (2017). Growth and Interaction of Normal Faults and Fault Network Evolution in Rifts: Insights from Three Dimensional Discrete Element Modelling. Geological Society, London, Special Publications. https://doi.org/10.1144/SP439.23

Published in:

Geological Society, London, Special Publications

\section{Citing this paper}

Please note that where the full-text provided on Manchester Research Explorer is the Author Accepted Manuscript or Proof version this may differ from the final Published version. If citing, it is advised that you check and use the publisher's definitive version.

\section{General rights}

Copyright and moral rights for the publications made accessible in the Research Explorer are retained by the authors and/or other copyright owners and it is a condition of accessing publications that users recognise and abide by the legal requirements associated with these rights.

\section{Takedown policy}

If you believe that this document breaches copyright please refer to the University of Manchester's Takedown Procedures [http://man.ac.uk/04Y6Bo] or contact uml.scholarlycommunications@manchester.ac.uk providing relevant details, so we can investigate your claim.

\section{OPEN ACCESS}


1 Growth and Interaction of Normal Faults and Fault Network Evolution in Rifts:

2 Insights from Three Dimensional Discrete Element Modelling

3 Emma Finch ${ }^{1} \&$ Rob Gawthorpe ${ }^{2}$

4 1. School of Earth Atmosphere and Environmental Science, University of Manchester, Oxford Road, Manchester, M13 9PL, UK

2. Department of Earth Science, University of Bergen, Allégaten 41, 5007 Bergen, Norway

\section{ABSTRACT}

The initiation, growth and interaction of faults within an extensional rift is an inherently four dimensional process where connectivity with time and depth are difficult to constrain. A 3D discrete element model is employed that represents the crust as a two-layered brittle-ductile system in which faults nucleate, propagate and interact in response to local heterogeneities and resulting stresses. Faults nucleate in conjugate sets throughout the model brittle crust; they grow through a combination of tip propagation and interaction of co-linear segments to form larger normal faults. Segment linkage occurs by merging of adjacent fault segments located along-strike, down-dip or oblique to one another. Finally, deformation localises onto the largest faults. Displacement distribution on faults is highly variable with marked along-strike and temporal variations in displacements rates. Displacement maxima continuously migrate as smaller fault segments interact and link to form the final fault plane. As a result, displacement maxima associated with fault nucleation sites are not coincident with the location of the maximum finite displacement on a fault where segment linkage overprints the record. The observed style of fault growth is consistent with the isolated growth model in the earliest stages which then gives way to a coherent (constant-length) fault growth model at greater strains.

Keywords

Discrete element modelling, rifting, normal fault, segmentation, fault growth and linkage 
31 Understanding fault evolution in three dimensions in rift basin settings is generally informed by interpretation and analysis of the current or final static fault geometry. The evolution and interaction of faults in extensional rifts, however, is an essentially four-dimensional problem, where the initiation, growth and interaction of faults in three dimensions through time modify the nature of the fault network. The aim of this paper is to apply a numerical model of rifting to better understand the nucleation, interaction and evolution of faults in four dimensions in a rift basin subjected to a single phase of extension. Using this model the propagation and interaction of faults, scaling relationships, progressive strain localisation and dip domain generation are addressed.

It is known that faults grow by lateral propagation and linkage where the slip on isolated and later linked faults accumulates at varying rates (McLeod et al. 2000; Cowie \& Roberts 2001; Walsh et al. 2003a). The processes involved are determined from interpretation of observable and extractable data at the end of either a single or multi-phase extension event. In particular, earthquake slip or displacement patterns along selected faults are used to infer the growth history and interaction of selected structures (Contreras et al. 2000; Sharp et al. 2000; Morley 2002; Manighetti et al. 2005; Bull et al. 2006; Jackson et al. 2006; Morley et al. 2007; Nicol et al. 2010; Reeve et al. 2015) with specific focus on relay structures (Acocella et al. 2000; Conneally et al. 2014; Fossen \& Rotevatn 2016) and the nature of fault tip interactions (Nixon et al. 2014b; Duffy et al. 2015; Whipp et al. this volume).

It is not straightforward to determine how faults in rift settings interact within the crust. For example, investigations of fault branching with depth in 3D seismic and analogue modelling have confirmed that what appear as isolated faults at the surface are, in fact, coupled along strike through structures at depth (Kornsawan \& Morley 2002; Soliva et al. 2008; Long \& Imber 2011, 2012; Giba et al. 2012). Failure to recognise this fact will lead to fault network statistics that do not accurately represent the largest faults or fault connectivity within the rift. A consequence of this will be an underestimate of earthquake rupture capabilities. (Walsh et al. 2003a; Manighetti et al. 2007; Soliva et al. 2008; Nicol et al. 2010).

Several lines of research suggest that faults originate in conjugate or polymodal orientations within an extensional rift and that the earliest forming faults modify the local stress field so that later neighbouring faults dip in the same orientation 
64 (Schlishe \& Withjack 2009; Healy et al. 2015). Dip domains evolve dependent on these self-organising incipient faults. Domain boundaries (also known as transfer/accommodation zones or graben shifts) are characterised by narrow zones of overlapping fault tips where a change in polarity is marked by interlocking arrays of conjugate faults (Schlische \& Withjack 2009; Kornsawan \& Morley 2002; McClay et al. 2002; McClay et al. 2005; Fossen \& Rotevatn 2016). Not all domain boundaries recorded between opposed dipping faults are considered to evolve from a selforganised state, however, for example where an underlying basement structure is present it has been shown to be a key influence on the location of domain boundaries (Accocella et al. 1999; Fossen \& Rotevatn 2016).

The mechanism required for faults within an evolving system to interact is generally discussed in terms of two fault models - the isolated model and coherent model (Walsh et al. 2003b; Giba et al. 2012; Fossen \& Rotevatn 2016). The isolated model suggests that a segmented fault array develops from random overlap and linkage of previously unrelated faults which initiate in a self-organised manner from natural heterogeneities and that strain is distributed homogenously (Cowie et al. 2000; Wu et al. 2015). According to the isolated fault model, faults develop during rifting from isolated heterogeneities within a rock volume by radial propagation and, as a result, individual segments of isolated structures expand laterally in three dimensions. As rifting progresses, these small, isolated, faults propagate rapidly to become larger structures or smaller faults link along strike and/or down dip through relays or tip propagation into larger structures (Peacock \& Sanderson 1991; Cartwright et al. 1995; Dawers \& Anders 1995; Wojtal 1996; Nicol et al. 1996; Gupta et al. 1998; McCleod et al. 2000; Cowie \& Roberts 2001; Walsh et al. 2003b). In the coherent model, a segmented fault array develops within an organised system in which segments are kinematically linked from the start. This has been demonstrated where some degree of strain concentration is present due to reactivation of a buried fault, influencing fault propagation in the overburden (Accocella et al. 1999; Walsh et al. 2003a; Giba et al. 2012). Fossen \& Rotevatn (2016) see these models as representative end members and not mutually exclusive. Jackson et al. (this volume) suggest that it is conceivable that pre-linkage faults propagate in accordance with the isolated model in their early stages, but that evidence for this is difficult to resolve from subsurface data sets and so the coherent model is more readily observed. 
97 Natural fault networks have been shown to exhibit specific scaling properties that are now key features in interpreting and modelling fault growth and interaction. These relationships are statistical descriptions of the distribution of the frequency-size of fault attributes, which include the correlation between the displacement on faults and their lengths, and the spatial patterns of faulting. Attention has focussed on evaluation and discussion of empirical relationships such as length, width, displacement and gouge thickness (e.g. Hull 1988; Dawers et al. 1993; Gross et al. 1997; Cowie \& Scholz 1992; Childs et al. 1993; Gillespie et al. 1992; Yielding et al. 1992; Torabi \& Støren Berg 2011; Xu et al. 2014). In natural and physical analogue fault networks, displacement-distance profiles are commonly employed to determine the timing of interaction of faults by along-strike linkage (Cowie \& Scholz 1992; Contreras et al. 2000; Ackermann et al. 2001; Cowie \& Roberts 2001; Faure Walker et al. 2009; Nicol et al. 2010; Nixon et al. 2011; Xu et al. 2014; Reeve et al. 2015; Jackson \& Rotevatn, 2013; Whipp et al. this volume). Displacement profiles for individual isolated faults show either triangular or elliptical profiles with displacement maxima at their centre (Marrett \& Allmendinger 1990). Symmetric displacementdistance profiles become asymmetric towards the interaction point where one tip is restricted, or form a double tip restricted, 'mesa'-style profile with steep edges when both tips are constrained (Dawers et al. 1993; Manighetti et al. 2005; Nixon et al. 2014b). Deviation of along strike profiles from hypothetical symmetric curves is thought to indicate the nature and timing of linkage of small fault segments into larger structures, where displacement maxima indicate centres of original smaller segments and minima denote points of linkage (Huggins et al. 1995; Faure Walker et al. 2009; Nixon et al. 2011; Nixon et al. 2014b; Xu et al. 2014; Reeve et al. 2015; Khalil \& McClay 2016). To maintain fault displacement-length scaling, it is expected that observed along-strike deficits in throw associated with fault linkage will become less significant as the fault grows (Nixon et al. 2014b; Jackson et al. this volume). An isolated type profile will result with a throw maximum at the centre of the new, larger structure (Contreras et al. 2000; Cowie et al. 2000; Faure Walker et al. 2009; Schlagenhauf et al. 2008; Xu et al. 2014).

Outcrop and subsurface (seismic) data provides a static, final image of fault networks. In order to assess how similar geometries evolve, physical and numerical analogues are used. Physical analogues examine the upper surface topographic and 
130 fault trace evolution through time and the final static fault geometry in cross section

131 (Acocella et al. 1999; Clifton et al. 2000; McClay et al. 2002, 2005; Hus et al. 2005;

132 Schlische \& Withjack 2009; Schlagenhauf et al. 2008; Henza et al. 2010, 2011).

133 These methods have been important in understanding fault growth and interaction

134 through time, but have not fully addressed the three-dimensional development of

135 fault networks.

136 Numerical methods use both two- and three-dimensional approximations to 137 investigate the interaction of either a large number of faults in a two dimensional 138 plane (Cowie et al. 2000) or focussed assessment of the growth and interaction of 139 selected pre-defined isolated structures (Walsh et al. 2001; Imber et al. 2004; Soliva 140 et al. 2008; Lovely et al. 2012; Allken et al. 2013). Discrete element models (DEMs) 141 are numerical models that use physically realistic inter-element interactions and have 142 been applied to model mechanical rock behaviour in scenarios where the evolution 143 of discontinuities can be tested (e.g., Cundall, 1971; Mora \& Place, 1993; Donzé et 144 al. 1996; Kuhn, 1999; Camborde et al. 2000; Toomey \& Bean 2000; Place et al. 145 2002; Imber et al. 2004; Hardy \& Finch, 2005 2006; Schöpfer et al. 2007a,b, 2009; 146 Longshaw et al. 2009; Abe et al. 2011; Lambert \& Coll 2014; Hardy 2014).

147 In this study, a discrete element model is applied to investigate the initiation, growth 148 and interaction of faults within a normal fault network in a rift basin. The crust is 149 represented as a two-layer model of passive crustal extension with an upper, $15 \mathrm{~km}$ 150 thick layer representing the brittle upper crust, and a lower $15 \mathrm{~km}$ thick, firmo-viscous 151 layer representing the ductile lower crust. The effects of thermal variation within the crust during the evolution of the model are not included. This approach allows investigation of fault nucleation and the subsequent organisation of a fault network in 4D, the 3D geometry and interaction between faults and the distribution of fault activity and displacement in time and space. Results presented have implications for analysis of natural fault systems, particularly the limitations of traditional methods for reconstructing fault growth histories from final fault geometry coupled with measurement of variations in displacement measured on pre- and syn-rift stratigraphic horizons along fault systems.

\section{METHODOLOGY}


162 Multi-layer rheologies in DEM techniques have been employed to examine the 163 influence of mechanical stratigraphy on the propagation of blind faults (Hardy \& 164 Finch 2007; Schöpfer et al. 2007a,b), boudinage (Komoróczi et al. 2013) and compressional wedges (Wenk \& Kuhn 2013). The crust in our model is represented as a two layer system where elements in the upper crust interact through linear elastic repulsive-attractive forces and those within the lower crust interact through linear viscous (Newtonian fluid) forces (Fig 1a) (Ranalli 1995). Elements in the upper crust are treated as an assembly of spheres that interact in pairs (ij) as though connected by breakable elastic springs following

$$
F_{i j U}^{\text {elastic }}=\left\{\begin{array}{c}
K(r-R), r<r_{b}, \text { intact bond } \\
K(r-R), r<R, \text { broken bond } \\
0, \quad r \geq R, \text { broken bond }
\end{array}\right.
$$

171 Where $K$ is the bond stiffness, $R$ is the equilibrium separation between an element 172 pair (element $i$ and neighbour $j$ ) and $r$ is the inter-element separation. Elements are 173 bonded until their separation exceeds a breaking distance, $r_{b}$, beyond which the 174 bond is broken and experiences no further attractive force but will experience a 175 repulsive force if the elements return to a compressive contact (i.e. $r<R$ ).

176 In the lower crust, a firmoviscous (Kelvin) body is applied to determine inter-element forces where elastic and linearly viscous forces are set in parallel (Fig. 1b). When loaded, the elastic response of the spring is delayed by the viscous response of the dashpot resulting in a non-instantaneous response. The force due to the spring in the lower crust, $F_{i j L}^{\text {elastic }}$, is obtained from

$$
F_{i j L}^{\text {elastic }}=\left\{\begin{array}{l}
K_{c}(r-R), r<R \\
K_{t}(r-R), r>R
\end{array}\right.
$$

where $K_{c}$ is the spring stiffness in compression, consistent with upper crustal elements, and $K_{t}$ is the spring stiffness in extension, set to zero. This relationship assumes that links between elements in the lower crust retain elastic properties in compression only. The viscous force is determined through

$$
F_{i j L}^{v i s c o u s}=-\eta \Delta \dot{x}
$$

where $\Delta \dot{x}$ represents the relative velocity between an element pair and $\eta$ is the 
187 velocity between an element pair, the greater the force acts to return them to their equilibrium position.

189 The total force, $F_{i}$, exerted on an element is obtained by summing the forces exerted 190 on it by its $n$ neighbours.

$$
F_{i}=\sum_{j=1, n} F_{i j U}^{\text {elastic }}+F_{i j L}^{e l a s t i c}+F_{i j L}^{v i s c o u s}
$$

191 The interface between the upper and lower crust is defined as a step function, 192 positioned at a depth appropriate to the thickness of the crust under investigation. 193 Bonds between elements that bisect this interface are treated as viscous. To 194 attenuate kinetic energy in the system and constrain the elastic nature of the springs, 195 a damping force, $F_{i D}$ is included

$$
F_{i D}=-v \dot{x}
$$

196 where $v$ represents the damping term and $\dot{x}$, the element velocity. The damping term 197 in this experiment is 7.0 (cf. 0.7; Potyondy \& Cundall, 2004) and permits the 198 investigation of quasi-static deformation (Donzé et al. 1994).

199 Finite element schemes have approximated the crust as a gravitating plate 200 effectively floating hydrostatically on the mantle (e.g. King \& Ellis 1990; Hassani \& 201 Chéry 1996). A similar method is employed here, where the crust is considered an 202 elastic-brittle-plastic plate floating hydrostatically on a fluid mantle held in equilibrium 203 around a specified depth (cf. King et al. 1988). This depth is determined from the 204 ratio between crust and mantle densities where the density of the brittle crust is 205 described as a lower estimate of crustal density based on the saturated bulk 206 densities of rock (King et al. 1988). The force experienced due to gravity and 207 floatation, $F_{G F}$, is added to the interaction force in the vertical, z-component direction 208 where

$$
F_{i G F}=g\left[\left(\rho_{m}-\rho_{c}\right) V_{B}-\rho_{c} V_{A}\right]
$$

209 Here $\rho_{c}$ and $\rho_{m}$ are crust and mantle densities respectively, $g$ is the acceleration due 210 to gravity, and $V_{A}$ and $V_{B}$ are the volume of the element that exist above and below 211 the hydrostatic equilibrium. When an element exists completely above the 212 equilibrium depth, a resultant downward force is experienced whereas an element 
entirely below the hydrostatic equilibrium experiences a resultant upward force simulating buoyancy.

With increasing time, the loading due to gravity will cause viscous flow in the lower crust. If the medium is not constrained in the $x$ - and $y$-component directions, this will cause a 'forcing out' of elements at boundaries. To negate this, the media is constrained by bounding walls which simulate it existing within a larger system of elements with similar mechanical properties. At each time step, if an element's interaction force oversteps the bounding limit for the wall, the element experiences an additional repulsive force from the wall. This wall force $\left(F_{i w}\right)$ assumes that element $i$ has come into a compressive contact with an element $w$, within the wall so that,

$$
F_{i w}=-K_{w} r_{w}
$$

where $r_{w}$ is equivalent to the amount by which the element exceeds the boundary and $K_{w}$ is the elastic stiffness of the wall (cf. Wenk \& Huhn 2013).

There are no shear forces determined within this technique, so the behaviour of the rock mass is considered as frictionless (see Mora \& Place 1994, Donzé et al. 1994; Hardy \& Finch 2007). This methodology has been previously used to successfully simulate the frictional stick-slip instability in a rock assemblage without shear forces (Mora \& Place 1994) and for biaxial compression tests and faulting in sedimentary successions above basement structures (Finch et al. 2003, 2004, Hardy \& Finch 2006). The success of these methodologies suggests that the assumption of a frictionless rock mass is not at odds with reproducing realistic rock mechanics behaviour. Other DEM techniques incorporate frictional forces but their addition greatly increases computational time (e.g. 45 days with 12000 elements, Wenk \& Huhn 2013).

The total force exerted on an element within the crust in the $x$ - and $y$-component directions is given through

$$
F_{i}^{\text {TOTAL }}=F_{i}+F_{i D}+F_{i W}
$$

The gravity and floatation term is included in the z-component direction; therefore the total force exerted vertically is

$$
F_{i}^{T O T A L}=F_{i}+F_{i D}+F_{i G F} .
$$


241 Extension is implemented on all elements in small increments to simulate movement

242 of a rigid boundary wall to the north while the southern boundary is static (Fig 1c).

243 The boundary condition is implemented so that

$$
y_{i}^{*}(t)=y_{i}(t)+\Delta y\left(\frac{y_{i}(t)}{y_{\max }(t)}\right) .
$$

Here, $y_{i}^{*}(t)$ is the new element location, $y_{i}(t)$ is the current element location, $\Delta y$ is the extension increment per timestep and $y_{\max }(t)$ is the maximum length of the model in the extension direction (similar to Donzé et al. 1994). Elements are advanced to new locations within the model by integration of their equations of motion using Newtonian physics (see Hardy \& Finch 2006). Discrete element models can be run in model units but for comparison with geological data, model units are often scaled to real world parameters (e.g. Place \& Mora 2001; Hardy \& Finch 2006). Numerical modelling of the effect of temperature variations on fault initiation and activity during rifting are common (Behn et al. 2002; Huismanns \& Beaumont, 2007; Wright et al. 2012). From these continuum mechanics based models, which employ thermo-mechanical equations to investigate fault localisation, it is known that extension results in crustal thinning and horizontal fluctuations in the temperature field culminating in focussed faulting around zones of thinned crust (Behn et al. 2002; Cowie et al. 2005; Huismans \& Beaumont, 2007). Deformation is distributed between sets of conjugate normal faults, however, in the absence of a regional temperature gradient (Behn et al. 2002). The purpose of this paper is to examine the initiation, growth and interaction of faults during rifting, and as such, localisation effects associated with thermal variations through time are not considered.

\section{Experimental set-up and data analysis}

\section{Discrete Element Model}

266 The experimental media consists of $1,080,000$ elements with a regular hexagonal 267 packing where element radii are unity (Fig 1). The initial dimensions are $213 \times 200 \times$ $268102(\mathrm{x}, \mathrm{y}, \mathrm{z})$ model units (m.u.). Horizons are defined as an integer value of their height in model units: there are 70 in total. Data from six horizons are extracted for discussion purposes, numbered from Horizon 52 (immediately above the upperlower crust boundary) to Horizon 102 (the upper surface) in ten-unit increments (Fig. 
272 1c). One model unit is equivalent to $292 \mathrm{~m}$ and the model represents real-world 273 dimensions of $64 \times 60 \times 30 \mathrm{~km}$. The upper and lower crust layers are each $15 \mathrm{~km}$ 274 thick at the start of the experiment. Experiments are run for 60,000 time steps with 275 data output at intervals of 1000 , providing 60 data files. A time step represents 100 276 years, so the total run time is $6 \mathrm{Myr}$ with an output interval of 100,000 years. The 277 southern end of the model is fixed. Extension is incremented at 0.001 unit per time 278 step towards the north (Fig. 1) and thus represents of rate of $3 \mathrm{~mm} \mathrm{yr}^{-1}$ with each 279 output correlating to $0.5 \%$ extension to a total of $30 \%$. The natural strain rate 280 determined for these experiments decreases from $1.6 \times 10^{-15} \mathrm{~s}^{-1}$ to $1.24 \times 10^{-15} \mathrm{~s}^{-1}$ 281 during extension, consistent with strain rates recorded from rifted basins, which can 282 range from $1.0 \times 10^{-16}$ to $4.0 \times 10^{-14} \mathrm{~s}^{-1}$ (Kusznir \& Park 1987; Nicol et al. 1997).

283 The data presented here are from a single experiment but are representative of 284 many experiments which evaluated scaling parameters appropriate for investigation 285 of the development of faults in a rifted basin. Rock densities are defined as 2800 $286 \mathrm{kgm}^{-3}$ and $3300 \mathrm{kgm}^{-3}$ for the crust and mantle respectively. The elastic spring 287 constant in the upper crust $(K)$ is $8.6 \times 10^{10} \mathrm{Nm}^{-1}$ and $9.7 \times 10^{11} \mathrm{Nm}^{-1}$ in the lower 288 crust $\left(K_{c}\right)$. For this scaling of the model, the Poisson's ratio is 0.25 and the Young's 289 modulus $(E)$ approximates to $90 \mathrm{GPa}$ and $105 \mathrm{GPa}$ in the upper and lower crust 290 respectively (Mora \& Place, 1994). Elements within the upper crust are randomly 291 assigned breaking thresholds $\left(r_{b}\right)$ between $0.025 \mathrm{~m} . \mathrm{u}$. and $0.1 \mathrm{~m} . \mathrm{u}$. at the start of the 292 experiment. The breaking threshold between element pairs is determined from the 293 average of the threshold assigned to the two elements, providing a distribution of 294 weak and strong bonds in varying orientations around each element. These breaking 295 thresholds scale to bond strengths between 2.1 and 8.6 GPa in the upper crust.

\section{Analysis of fault network development}

297 Faults are defined by analysing the separation between an element and its 298 immediate neighbour in the extension direction at the end of the experiment. They 299 are identified by filtering data for each element relative to heaves exceeding $50 \mathrm{~m}$ 300 and recording the throw (vertical displacement between element pairs). In previous 301 methodologies (e.g. Finch et al. 2004; Hardy \& Finch 2006), faults have been 302 defined using continuous alignments of broken bonds. In this experiment, however, 303 displacement propagates into the lower crust where bonds do not break. Therefore a 304 filter using fault heave was deemed the most appropriate method for determining 
305 fault locations. The heave value used has been chosen through testing and prevents 306 fault definition including elements displaced by flexural rotation of horizons in 307 hangingwalls and footwalls. A fault in this model is defined as a continuous 308 alignment of elements with similar dip orientation along strike (north or south). The 309 chosen elements are then assigned a fault number. Data associated with these 310 faults can be extracted from earlier outputs within the experiment to determine the 311 growth and interaction of selected structures. For example, the topographic evolution 312 associated with a fault at the surface can be analysed by outputting displacement on 313 its constituent elements to produce displacement-distance plots for throw at times 314 throughout the experiment.

315 For each horizon in the model, 120 1D transects perpendicular to the extension 316 direction can be extracted. The throw and heave of faults that intersect these 317 transects can be assessed through time and employed to examine fault growth, 318 strain accommodation and fault polarity. This is carried out for the upper surface 319 (Horizon 102) to compare with data from fault analysis techniques. Fault 320 displacement is output for five selected transects to demonstrate fault growth at the 321 upper surface. The amount of strain accommodated on north- and south-dipping 322 structures is determined from the summation of fault heaves along these transects. It 323 is recorded against time and the relationship between dip direction and strain 324 accommodation is plotted.

325 The polarity of the five selected 1D transects is calculated using

$$
P=\frac{\varepsilon_{d}-\varepsilon_{n}}{\varepsilon_{t}}
$$

where $\varepsilon_{d}$ and $\varepsilon_{n}$ are the strain accommodated by the dominant and non-dominant strain orientation and $\varepsilon_{t}$ is the total strain accommodated along the transect. Similar to Moriya et al. (2005), the dominant fault direction is defined as the direction in which the largest displacement fault dips. In this respect, $-1.0<P<1.0$, where a population that is strongly polarised opposite to the dip of the largest fault will return polarities approaching -1.0 and a population that dips consistently with the largest 332 fault will return polarities near 1.0. As a consequence, the orientation that contains 333 the fault with the largest strain should be consistent with the dominant direction of 334 strain accommodation, indicating that a positive $P$ value should be expected. 
335 To illustrate fault evolution and linkage in three dimensions, the displacement (throw)

336 on elements that constitute six selected faults is plotted in strike sections at $15 \%$,

$33720 \%, 25 \%$ and $30 \%$ extension. Displacement-distance plots for these faults is

338 presented where data is generated by sampling within $500 \mathrm{~m}$ intervals along the

339 length of a fault, recording the maximum displacement regardless of depth for each

340 interval. This is done to negate the dominance of one horizon in assessment of fault

341 growth and highlights the location of displacement maxima through time along the 342 fault length.

344 FAULT NETWORK ORGANISATION

345 In this section, a number of features of the organisation and growth of the fault 346 network are presented. We firstly look at fault nucleation and then evaluate the entire 347 fault network in relation to the spatial distribution of faults, their growth and 348 interaction. Displacement accrual along selected transects, fault polarity and strain 349 accommodation across dip domains and domain boundaries is then considered. 350 Fault network statistics are presented in relation to the variability with depth of the 351 frequency-size relationship, displacement on selected horizons and displacement on 352 the largest faults within the system. The final section discusses the along-strike 353 three-dimensional interaction of seven faults.

\section{Fault nucleation}

356 In order to assess whether lattice geometry affects the nucleation and growth of 357 faults, the location of the earliest bond failures are output relative to depth and orientation (Fig. 2). These nucleation sites are distributed throughout the brittle layer and demonstrate that there is no dominance or focus in the distribution of initial failures with depth (Fig. 2a) or their orientation (Fig. 2b). The location of further failure in the brittle layer continues with increasing extension and is distributed throughout the crust, influenced by the stress fields surrounding existing faults. 
366 The consequence of faults initiating in a conjugate distribution is shown in Fig. 3

367 where the elements that constitute the final faults in the model are shown. Faults are 368 connected along strike through a curvilinear geometry and spaced at regular intervals. By the end of the experiment, larger faults fill the brittle crust with maximum displacement at their centres ( $\mathrm{H} 72$, Fig. $3 b)$. The depth to which faults project into the lower crust varies according to their along-strike length. Upper surface topography forms a series of grabens and half-grabens where basins have a maximum along-strike length $<30 \mathrm{~km}$ and footwall crest to footwall crest separations of around 10-15 km (Fig. 3c). Hangingwall depocentres are located at fault centres with maximum relief on the order of a kilometre. Conjugate fault interactions across relays are common and numbered circles highlight three locations where relays result in topographic lows between neighbouring basins (Fig. 3c and 4).

Fault network growth and organisation

The evolution of the fault network on the uppermost horizon (H102) together with topography and dip domains is shown in Fig. 4. Faults initiate as a large number of small, isolated structures, striking perpendicular to the extension direction $\left(+/-20^{\circ}\right)$, and by $10 \%$ extension have lengths and separations on the order of $10-15 \mathrm{~km}(10 \%$, Fig. 4a). Displacement on these faults generates small footwall crests and hangingwall depocentres with relief <100 m (10\%, Fig. 4b) and faults form conjugate sets (10\% extension, Fig. 4c). At the end of rifting (6 Myr, 30\% extension), there are no faults at the upper surface that rupture the entire width of the model; the largest faults are $\sim 30 \mathrm{~km}$ long (30\% extension, Fig. 4c).

Fault growth and interaction is indicated by the timing of bond failure (Fig. 4a). Following initial fault growth (grey colouring, 10\%, Fig. 4a), further bonds break as the early formed faults propagate laterally (green colouring, 20\%). Bond failure in the final $10 \%$ extension is focussed on the propagation and linkage of faults, either along strike, or by breaching existing relays (yellow-red colouring, 20-30\%). Topography evolves from small isolated basins with relief ranging from $\leq 100 \mathrm{~m}$ (10\% extension,

394 Fig. 4 b) to large $20-30 \mathrm{~km}$ long basins with up to a kilometre of displacement on individual faults and hangingwall depocentres (purple) focused mainly at fault centres (30\% extension, Fig. 4b). The conjugate pattern established during fault nucleation (Fig. 2) results in the surface being divided into dip domains whose boundaries trend sub-parallel to the extension direction (30\%, Fig. 4c). Faults in the 
centre of the model dip predominantly southwards (red, Fig. 4c), whereas those either side of this central area dip mainly northwards (blue, Fig. 4c). Conjugate fault interactions shown in Fig. 3 coincide with two of these domain boundaries (circles 2 and 3, 30\% extension, Fig. 4).

The growth and interaction of faults at this horizon is presented through the development of structures in three regions (A-C, Fig. 4a). Region A highlights the along-strike linkage of two south-dipping faults from a relay ramp (10\% extension) to a single-breached relay on its southern boundary (20\% extension) through to a double breached relay at $30 \%$ extension (Fig. 4). As a consequence, there is increased hangingwall subsidence and bed rotation at the point of linkage (20-30\% extension, Fig. 4b) and increased dip on the fault (intense red colour, 20-30\% extension, Fig. 4c).

Region B contains one north-dipping fault and eight south dipping faults that by $10 \%$ extension, have lengths $<5 \mathrm{~km}$ (Fig. 4a). At $20 \%$ extension, the south-dipping faults (red, Fig. 4c) have soft-linked and comprise four segments separated by relay ramps (Fig. 4a-c). These then breach and form one structure, with the eastern tip being constrained by a conjugate, north-dipping fault (circle 3, 30\% extension, Fig. 4a-c) and the western tip interacting with another north-dipping fault (30\% extension, Fig. 4c). The growth of these and neighbouring faults are later used to illustrate threedimensional fault evolution and interaction (Figs. 11-16). Region C (10\% extension, Fig. 4c) highlights four faults which are used to demonstrate the along-strike linkage and interaction of faults relative to surface topography (Figs. 5, 7 and 8).

Five representative transects across the upper surface are used to demonstrate variability in the growth of faults (1-5, Fig. 5a). Selected faults (B-F) presented in later figures are coloured to illustrate their growth. Bold dotted lines indicate faults that rapidly accumulate displacement which then decrease or plateau (Fig. 5b). This shows that the largest fault on any transect at the start of rifting does not necessarily continue to dominate with time and other factors may control which faults in the network are dominant with increasing strain. Solid bold lines indicate selected structures where the displacement is initially small and accelerates with time. The remaining faults encountered (coloured grey) have low displacements (<200 m) and become inactive during rifting, shown by little/no increase in displacement with time. Faults $E$ (blue) and $F$ (green) show a general trend of increasing displacement with 
432 time, similar to faults represented by the bold solid lines (Transects 1-5, Fig. 5). Fault

$433 \mathrm{C}$ (purple) on Transect 2 is one of the largest faults until $4.5 \mathrm{Myr}$, at which point the 434 displacement becomes fixed around $400 \mathrm{~m}$ and its displacement rate slows. This 435 correlates to the growth of neighbouring Faults B (red) and D (yellow) shown in 436 Transects 1-3 (displacement increases after 4 Myr, Fig. 5b) and is discussed later 437 (Figs. $7 \& 8$ ).

438 As rifting progresses, a series of dip domains (i.e. regions of similar fault dip 439 direction) develop without any pre-existing fabrics or lineaments (Fig. 4c). The strain 440 accommodated relative to the dip direction of faults is shown for Transects 1-5 in Fig. $4416 a$. The variability and conjugate nature of faults during early rifting is again 442 highlighted (<2Myr, 10\% extension, Fig. 4), with all transects displaying changes in 443 the dominant orientation of strain accommodation before 2 Myr (Fig. 6a). Three 444 transects have a dominant dip direction (Transects 1, 2 and 4, Fig. 6b). In Transects 4451 and 2 up to $80 \%$ of the strain is accommodated by north-dipping faults, consistent 446 with the western, north-dipping domain shown in Fig. 4c. Transect 4 represents the 447 central south-dipping domain from Fig. 4c where, from an early stage of rifting, the 448 greater amount of strain is accommodated by south-dipping faults. Strain 449 accommodation along Transects 3 and 5 is more complicated, however, since they 450 intersect domain boundaries. The percentage of strain accommodated fluctuates 451 around 50\% for up to 4.5 Myr (Transect 3) and 3.5 Myr (Transect 5) and implies that 452 the relative growth and interaction of faults at domain boundaries directly affects 453 strain accommodation in these zones. Later in rifting they localise to a 60:40 454 relationship dipping north (Transect 3) and south (Transect 5) suggesting the fixing 455 of dip domains is not yet complete.

456 The polarity of faults on representative transects is shown in Fig. 6b. Transects 1, 2 457 and 4 (Fig. 5a) which are contained within a strong dip domain (Fig. 4c) show a 458 mainly positive correlation between the dip direction of the dominant fault and main 459 strain accommodation direction. The initial 3 Myr show an increasing linear 460 relationship between polarity $(P)$ with time which levels off where $0.5<P<0.6$ as rifting 461 continues. In Transects 2 and 4, polarity switches to negative in the final 0.5 Myr (25$46230 \%$ extension) suggesting that the dominant fault has changed to one that dips in 463 an opposite direction. This implies that within a strong dip domain, there is the 464 possibility for faults antithetic to the dominant strain accommodation direction to 
465 continue to accumulate displacement. The polarity of Transects 3 and 5, as expected 466 from the strain accommodation data and their location at domain boundaries, 467 fluctuates between positive and negative as faults interact.

Fault interaction and displacement rate evolution

The preceding results showed that some of the largest faults at the initiation of rifting become inactive as neighbouring faults grow around them (e.g. Fault C, Fig. 5a). Fig. 7 focusses on the growth of fault segments within Region C in Fig. 4. Faults $C$ and D are the largest faults with lengths $\geq 10 \mathrm{~km}$ at $15 \%$ extension and maximum displacement of $150 \mathrm{~m}$, all other faults segments have lengths $<3 \mathrm{~km}$. From 15 to 20\% extension (3-4 Myr, white band, Fig. 7b) Faults C and D have the greatest displacement, with two segments of Fault $D$ propagating laterally and increasing displacement up to $400 \mathrm{~m}$, overtaking Fault C $(250 \mathrm{~m})$. Fault B comprises a number of small soft-linked segments at this stage (displacement $<200 \mathrm{~m}$ and $<8 \mathrm{~km} \mathrm{long}$ ). Fault $A$ is a conjugate fault that interacts with Fault $B$ at the surface and is $\sim 3 \mathrm{~km}$ long and has displacement of $<150 \mathrm{~m}$.

Displacement on Fault C markedly slows after 4.0 Myr as the initial segments of Faults A, B and D propagate laterally (25\% extension, Fig. 7a) and link (thickening of 4-5 Myr band, Fig. 7b). From 5-6 Myr (25-30\% extension), Fault A continues to grow, the soft-linked segments of Fault B link, and the two segments of Fault D propagate along-strike. The profiles of these faults are consistent with profiles of natural examples. Faults $A$ and $D$ have triangular displacement profiles where their lateral tips are restricted (cf. Fig. 8. Nixon et al. 2014b), Fault B has an asymmetric profile where its eastern tip is restricted by interaction with Fault $A$ (point 2, Figs. 4c \& 7a) and Fault $\mathrm{C}$ represents a traditional symmetric displacement profile consistent with an isolated fault. Before $20 \%$ extension Faults A, B and D grow laterally while accruing displacement exhibiting a growth pattern resembling the isolated fault model. Fault $\mathrm{C}$ however, attains its length rapidly and then accrues displacement, suggestive of the coherent growth model, although growth of this fault slows as neighbouring faults dominate at greater extension.

The displacement rates of Faults A, B, C and D at intervals of $1 \mathrm{Myr}$ are shown as strike projections in Fig. 8a, and summarised as a displacement versus time plot for 
selected profiles in Fig. 8b. The main period of fault growth differs for each fault and along-strike rates vary dramatically. Faults $A$ and $B$ have a maximum displacement rate between 4 and $6 \mathrm{Myr}$, when their lateral propagation and interaction causes an increase from $<0.1 \mathrm{~mm} \mathrm{yr}^{-1}$ up to $0.37 \mathrm{~mm} \mathrm{yr}^{-1}$. The hard-linkage of segments that constitute Fault B at $4 \mathrm{Myr}$ is shown by the pink profile $(21,000 \mathrm{~m}$, Fig. 8a), with displacement rates increasing from 0 to $0.15 \mathrm{mmyr}^{-1}$ at $4 \mathrm{Myr}$ to $0.3 \mathrm{~mm} \mathrm{yr}^{-1}$ between 5 and 6 Myr. Further linkage on Fault B between 5 and 6 Myr is shown by the red profile $(16,000 \mathrm{~m}$, Fig. $8 \mathrm{a})$ where the displacement rate increases rapidly from 0.08 $\mathrm{mm} \mathrm{yr}^{-1}-0.37 \mathrm{~mm} \mathrm{yr}^{-1}$. By comparison, the neighbouring parts of the fault propagate from $0.15 \mathrm{~mm} \mathrm{yr}^{-1}-0.3 \mathrm{~mm} \mathrm{yr}^{-1}$.

The displacement rate on Fault C peaks at 4 Myr (dark grey, Fig. 8a) at $0.15 \mathrm{~mm} \mathrm{yr}^{-1}$ and then decreases in the last 2 Myr of extension to $<0.03 \mathrm{~mm} \mathrm{yr}^{-1}$ showing that this fault is almost inactive at the end of rifting despite initially being the largest (Figs. 7 \& 8). The most complicated pattern of growth is associated with Fault D. Up to $4 \mathrm{Myr}$, there are two distinct segments where each has a displacement rate maximum at its centre (Fig. 7b). The blue, green, and purple profiles demonstrate an increasing displacement rate before $4 \mathrm{Myr}$, which then stays constant or decreases. The alongstrike growth and linkage of this fault (seen at 20-30\% extension, Fig. 7 a,b) is shown by increased displacement rate in the shaded region (Fault D, Fig. 8a) and increases in displacement rate for the orange, pink and black profiles between 5 and $6 \mathrm{Myr}$.

\section{Fault network statistics}

The maximum recorded displacement for six selected horizons in the crust (H52$\mathrm{H} 102)$ is shown Fig 9 at $500 \mathrm{kyr}$ (2.5\% extension) intervals from 2 to 6 Myr. Before 4 Myr (20\% extension) the maximum displacement recorded on these horizons is depth invariant and $\sim 600 \mathrm{~m}$. As rifting continues, the range of maximum recorded displacement increases to between 750 and $1500 \mathrm{~m}$, where the largest are focused around Horizon 72 (the depth of the centre of the largest faults). This suggests that small faults (displacement $<600 \mathrm{~m}$ ) in the fault network accommodate the majority of the strain prior to $20 \%$ extension (4 Myr) distributed throughout the brittle layer and no large displacement (> $800 \mathrm{~m}$ ) faults exist. The coalescence of these small, distributed, isolated faults into larger, crustal scale structures occurs between 20 and 
$52925 \%$ extension where the maximum displacements on horizons start to localise around mid-crustal depths $(\mathrm{H} 62-\mathrm{H} 82)$. The last million years (5\% extension) is characterised by localisation of strain (and displacement) onto these large faults that bisect the upper crust.

The maximum displacement recorded on the 30 largest faults is plotted in log-log

\section{Distribution of linked conjugate faults in three dimensions}

To demonstrate the complexity of interactions between faults in three dimensions, a representative group of seven faults centred on Faults $E$ and $F$ (Region B in Fig. 4c) have been extracted (Fig. 11). This region contains three major faults $>40 \mathrm{~km}$ long (Faults $\mathrm{E}, \mathrm{F}$ and $\mathrm{K}$ ) and four minor faults $<20 \mathrm{~km}$ long (Faults $\mathrm{G}, \mathrm{H}, \mathrm{I}$ and $\mathrm{J}$ ). The south-dipping faults ( $\mathrm{G}, \mathrm{H}$ and $\mathrm{I}$ ) are antithetic to and intersect the larger northdipping Fault E. Each of these faults is influenced by and interacts at depth with either of the north-dipping Faults $\mathrm{J}$ and $\mathrm{K}$ (Fig. 11 b,c). Few faults are linear along strike; most follow a curvilinear path from east to west controlled by their constituent fault segments. Intersections are at varying depth and not focussed in one horizon (white dotted lines, Fig. 11 a, d \& e). At the end of rifting, displacement maxima for the two largest faults ( $E$ and $F$ ) are focussed towards their centre with depth. The relative position and nucleation time of neighbouring faults controls their down-dip and along-strike continuity (Fig. $11 \mathrm{~d}, \mathrm{e})$.

The spatial distribution with depth at the end of the experiment for Faults $E$ to $K$ is shown in Fig. 12. The major faults ( $E$ and $F$ ) are present on the upper horizon, where Fault $E$ is represented by two separate $\sim 20 \mathrm{~km}$ long segments to the west and east, divided along strike by Fault $F$. This is consistent with the gap in the upper elevation of Fault $E$ in strike projection (Fig. $11 \mathrm{~d}, e$ ). Fault $F$ terminates against the 
561 hangingwall of Fault $E$ at its eastern tip (white circle, Fig. 12a, circle 3, Fig. 4).

562 Depocentres associated with these faults are $750 \mathrm{~m}$ below the mean elevation, and 563 prominent footwall crests have developed. The other major fault $(K)$, to the south is 564 represented by four segments at this elevation.

565 At $2.5 \mathrm{~km}$ depth, Fault $\mathrm{E}$ remains as two separate segments to the west and east 566 with a number of smaller branches at its tip with the eastern segment terminating 567 against Fault $F$ (white star, Fig. 12b). At a depth of $5.1 \mathrm{~km}$, Fault $E$ is $60 \mathrm{~km}$ long and 568 connects the two segments at higher horizons (Figs. 11d \& 12c). It has a 569 pronounced depocentres associated with the upper segments and a number of 570 branches along its length (white stars, Fig. 12c). White circles along its length show 571 where the tips of the south-dipping Faults $\mathrm{G}, \mathrm{H}$ and I are in contact with it forming small grabens. Lateral continuity of Fault $E$ is most pronounced at a depth of $7.8 \mathrm{~km}$ where antithetic Faults G, H and I are coincident with the strike of Fault $\mathrm{E}$ (white circles, Fig. 12d). At depths of 10-12 km, Fault E bifurcates again into two segments - one to the west ( $\sim 15 \mathrm{~km}$ long) and the other to the east ( $40 \mathrm{~km}$ long $)$ - separated by a south-dipping fault indicated by an intermediate crest in the topography between segments (Fig. 12 e,f).

Fault F dips southward and is most laterally continuous in its upper region (Fig. 11e), with Fault $\mathrm{H}$ tracking it at a constant distance of around $8 \mathrm{~km}$ to the north (Fig. 12). With depth, Fault F interacts with Fault $\mathrm{K}$ to the south, which inhibits its propagation, and it branches into two segments (dotted lines and central gap, Figs. 11e and 12df). The mid-crustal section of Fault $F$ is constrained to the east by the conjugate, north-dipping, Fault J (Fig. 12 c,d).

At the deepest horizon shown on Fig. $12(-12.1 \mathrm{~km})$, all seven faults (E-K) are present. The minor conjugate Faults $\mathrm{H}$ and $\mathrm{J}$ are in contact, Fault I cuts the eastern margin of the half-graben between Faults $E$ and $J$ and Fault $G$ is at its maximum length (uninhibited by neighbouring faults), forming a $\sim 20 \mathrm{~km}$ long graben with Fault $588 \quad K$ to the south (Fig. 12f).

Fault growth and interaction in three dimensions

591 The ability to extract displacement on elements with time means that the growth and 592 interaction of faults can be investigated. Strike projections of displacement at $5 \%$ 
593 intervals of extension from 15 to $30 \%$ are shown in Figs. 13-15, allowing fault 594 nucleation and growth to be assessed. In the following section, we focus on Faults $E$ 595 and $\mathrm{F}$ (Figs. 7a, 11, 12), describing their evolution and interaction with adjacent 596 faults in the network.

597 At 15\% extension Fault $\mathrm{E}$ is composed of six small isolated fault patches (1-6; Fig. 598 13a) that have nucleated at varying depths in the upper brittle crust. Only two 599 patches intersect the upper surface (2 and 5). At this stage in their evolution these 600 patches have displacement maxima of 200-300 m occurring near their centres, and 601 displacement decreases towards their tips (Fig. 16a). These patches range in strike 602 length from 3.5 to $8 \mathrm{~km}$, have aspect ratios (vertical:horizontal) from 1:1 to 2:1, and 603 are separated along strike by relatively unfaulted regions 2 to $10 \mathrm{~km}$ wide. No faults 604 initiate in the lower crust, although patches 3, 4 and 6 are located close to the upper605 lower crust interface.

Between 15 and $20 \%$ extension, displacement maxima on these patches have increased to between 300 and $750 \mathrm{~m}$. All fault patches have grown outward from their nucleation sites, and despite varying degrees of interaction, displacement maxima are still located at the centre of the six initial patches (light blue, Fig. 13b). Patches 1 to 4 show largely radial growth, and maintain similar aspect ratios, although downward propagation of fault patch 2 is inhibited by interaction with Fault G (cf. Figs. 13b \& 14b). In contrast, patches 5 and 6 begin to hard link into a single $20 \mathrm{~km}$ fault segment. Patch 5 in particular shows preferential growth downward and eastward towards patch 6 , and its displacement maximum has migrated deeper into the crust. In contrast, the western side of patch 5 remains relatively fixed in position due to interaction with Fault F (cf. Figs. 5a, 11a, 13b \& 15b).

After $25 \%$ extension, Fault E comprises three major fault segments, 20-25 km long, with up to $1500 \mathrm{~m}$ displacement, separated by segment boundaries associated with marked displacement deficits (Figs. 13c, 16a). The three major fault segments have evolved by hard-linkage of earlier patches 1 and 2 (western segment), 3 and 4 621 (central segment) and 5 and 6 (eastern segment) (Fig. 13c). The western segment still has a significant displacement deficit at the former segment boundary between the two precursor patches (1 and 2). In contrast, displacement deficits associated with boundaries between the precursor segments of the central and eastern segments have largely been removed (Fig. 16a). The eastern and western segments 
rupture the full thickness of the upper crust and extend into the lower crust, although downward propagation of the western segment is inhibited by Fault G (Fig. 14c). A more striking interaction that affects growth of Fault $E$ is the upward propagation of its central segment. This segment of the fault remains blind. It only ruptures the lower half of the brittle crust, and its upward propagation is inhibited by the presence of Fault $F$ above it to the south (cf. Figs. 11, 12a, 13c, 15c \& 16).

At the end of rifting (30\% extension), Fault E extends across the entire width of the model (Fig. 13d), and shows an overall increase in displacement rate compared to earlier in its evolution (Fig. 16a). Although it is hard-linked at depth, it is still blind along its central section, where it is overlain by Fault $F$ and thus appears as two distinct faults separated along strike by over $20 \mathrm{~km}$ (cf. Fault E, Figs. 5a \& 12a). Displacement maxima up to $2500 \mathrm{~m}$ occur at three locations along its length, coinciding with map-view locations of precursor patches 1, 3 and 5 but now localised near the base of the upper crust (Fig. 13c). Displacement minima are still evident at segment boundaries between the three segments present at $25 \%$ extension, although the displacement deficit between patches 1 and 2 in the western segment has been removed by this time (Fig. 16a).

The evolution of Fault $F$ shares many similar characteristics with Fault $E$ (Fig. 13). It initiates as five patches (7-11; Fig. 15a) that occur at a range of depths within the brittle crust and initially propagate outward and then link to form major fault segments. Patches 7 and 10 occur at mid- to deep-crustal levels, whereas patches 8,9 and 11 are shallower (Fig. 15a). At mid- to deep-crustal levels, Fault $F$ is crosscut along its length by Fault $\mathrm{K}$ which accounts for gaps in its lateral continuity (e.g. above patch 7 and below patch 9, Figs. 11a \& 12). Patches 8 and 9 become hardlinked by $20 \%$ extension and the boundary between them loses its displacement deficit by $25 \%$ extension (Figs. 15 b,c \& 16c). In contrast, linkage between patches 7 and 8 occurs later, with rapid accrual of displacement on patches 7 and 8 between 27.5 and 30\% extension (Fig. 16c). On the eastern side of Fault F, patches 10 and 11 link between 15 and $20 \%$ extension, and the displacement deficit between them is lost by $22.5 \%$, giving rise to a single prominent displacement maximum (Figs. $15 \mathrm{c}$ $\& 16 c)$. This growth and linkage history creates two major fault segments for Fault $F$ by $25 \%$ extension with a major displacement low between precursor patches 9 and 10 that exists throughout the evolution of the model (Fig. 16c). This long-lived 
displacement low is due to interaction with the underlying Fault $\mathrm{K}$, dipping from the north. As with Fault $\mathrm{E}$, at $30 \%$ extension, displacement is localised towards the middle of the fault at the base of the brittle layer (e.g. Fig. 15d).

The evolution of other faults in the region surrounding Faults $E$ and $F$, i.e. Faults $G$, $\mathrm{H}, \mathrm{I}$ and $\mathrm{J}$, is shown in Figs. 14, 15 and 16b,c. The main difference between these faults and Faults $E$ and $F$ is that their lengths are fixed relatively early during extension. Fault $G$ initiates at a mid-crustal depth, similar in depth to patches 3 and 4 on Fault E (cf. Figs. 13a \& 14a). It propagates down dip with a small patch of slip propagating up dip toward Fault $E$ between patches 2 and 3 , but it does not propagate upward and break the surface because it lives in the stress shadow of neighbouring faults to the north. The displacement maximum for Fault $\mathrm{G}(1400 \mathrm{~m})$ is on the upper, western part of its surface, rather than lying centrally, a function of it abutting and interacting with the blue fault. Similar to Faults $E$ and F, Fault G shows an increase in displacement rate between $20 \%$ and $30 \%$ extension (Fig. 16b). Fault $\mathrm{H}$ initiates in the upper part of the brittle layer and propagates largely down dip until $20 \%$ extension. Its length then increases from 15 to $24 \mathrm{~km}$ during the final $10 \%$ extension by near-surface westward propagation. In contrast, Faults I and J show a different style of evolution marked by an overall decrease in displacement rate through time, particularly during the last 5-10\% extension associated with their tip restriction against the major faults, $E$ and $F$. This is the time when the major faults display an increase in displacement rate (Fig. 16b).

The displacement profiles of Faults $E$ to $J$ through time illustrate a number of features of the development of the fault network (Fig. 16). The final along-strike profile for Fault $E$ shows two displacement minima at distances of $20 \mathrm{~km}(\sim 500 \mathrm{~m}$, between patches 2 and 3, Fig. 16a) and $40 \mathrm{~km}(\sim 1 \mathrm{~km}$, between patches 4 and 5, Fig. 16a). The westernmost minimum is associated with interaction and displacement relative to the antithetic Fault G (Figs. 11d, 12d \& 16b). The reduction around $40 \mathrm{~km}$ (patches 4 and 5, Fig. 16a) is coincident with the surface expression of Fault $F$ and Fault $H$ to the north (patches 10 and 11, Fig. 16c). The final profile of Fault $G$ represents an isolated fault with maximum displacement at the centre diminishing to the tips. The minor faults $(\mathrm{H}, \mathrm{I}$ and $\mathrm{J})$ show asymmetry associated with single tip restrictions. The displacement profiles of Fault $E$ (patches 3-6) and Fault $F$ (patches 7-9) have steep shoulders associated with faults restricting their 
692 propagation to both the east and west despite hard-linking to neighbouring sections

693 through displacement minima along strike (Fig. 16a \& c).

\section{DISCUSSION}

696 In this model of a single phase of extensional rifting we have observed four stages of 697 fault growth and interaction. We term these stages: (1) nucleation, (2) propagation 698 and interaction, (3) linkage and domain fixing, and (4) localisation (Fig. 17).

699 In Stage 1 (Fig. 17a), a large number of small conjugate faults (< $5 \mathrm{~km}$ in length) 700 nucleate rapidly, at varying depths in the crust. These faults develop as isolated 701 fault segments that have elliptical displacement contours with displacement maxima 702 at their centres, striking sub-perpendicular to the extension direction. In Stage 2 (Fig. 703 17b), these isolated fault segments propagate and interact with one another. 704 Individual segments that are co-linear begin to link along strike or down dip (lengths $705 \sim 15 \mathrm{~km}$ ), and relay ramps develop at fault tips as a result of soft-linking of fault 706 segments. Where faults have opposing dip, lateral propagation is inhibited. By Stage 7073 (Fig. 17c), distinct grabens and half-grabens are developed in the hangingwalls of 708 larger faults. These larger faults (lengths $\sim 20 \mathrm{~km}$ ) formed by the linkage of co-linear 709 fault segments. At the fault network scale, dip domains become well established and 710 their boundaries become fixed. The boundaries between the dip domains form 711 narrow zones where conjugate faults interact and lateral propagation is inhibited. In 712 the final stage of fault network evolution, Stage 4 (Fig. 17d), activity is localised on a 713 small number of large faults (lengths $>40 \mathrm{~km}$ ) that cut across the entire upper, brittle 714 crust. Some faults that were initially dominant become inactive at this time. These 715 are generally located in the strain shadow of faults that grow more rapidly during this 716 stage of fault network evolution. In this final stage, a pronounced increase in 717 displacement rate on the large active faults is observed and displacement maxima 718 migrate to their centres.

719 In the following sections we discuss the results of our 3D numerical modelling in 720 comparison to natural examples and other analogue and numerical models of fault 721 growth. We specifically discuss: i) comparison to natural and analogue fault 722 systems, ii) fault growth, propagation and linkage, and iii) fault network and dip 723 domain development. 


\section{Comparison to natural and analogue fault systems}

726

727

728

729

730

731

732

733

734

735

736

737

738

739

740

741

742

743

744

745

746

747

748

749

750

751

752

753

754

755

Many of the characteristics of the growth and linkage of the normal fault segments reported here are comparable to those from other modelling approaches (e.g. Cowie et al. 2000) and from studies of natural fault systems in the subsurface (e.g. Young et al. 2001) and outcrop datasets (e.g. Gawthorpe et al. 2003). The strain rate in the model decreases with time from $1.6 \times 10^{-15} \mathrm{~s}^{-1}$ to $1.24 \times 10^{-15} \mathrm{~s}^{-1}$ and is comparable with the natural strain rate observed in rifts such as the Gulf Coast and Aegean (Fig. 18). The displacement rates for the 30 largest faults in the model plot are similar to the natural data. Nicol et al., 1997 demonstrated that there is a broad correlation between regional strain rate and fault displacement rates suggesting increased strain rate is accommodated by increased displacement rate rather than an increased number of faults. This is observed in our model, where strain localises onto the largest faults as rifting progresses.

In addition to the growth and linkage of fault segments, a number of other features of the model replicate features described in other studies of normal fault geometry and growth. These include the spacing of faults and fault interactions, the form of displacement profiles along the faults, and fault scaling relationships.

Fault spacing parallel to the extension direction is on the order of $5-20 \mathrm{~km}$ after $30 \%$ extension, and relay breaching occurs at 10-20\% extension where fault tip separations are $<3 \mathrm{~km}$ (Fig. 4b). Fossen \& Rotevatn (2016) suggest that where the thickness of the brittle upper crust is $10-15 \mathrm{~km}$, as in this model, spacing between major extensional faults is expected to be around $5 \mathrm{~km}$. Similar thickness to spacing ratios are observed in a range of natural examples and in scaled sandbox experiments (Morley 2002; Hus et al. 2005; Conneally et al. 2014; Nixon et al. 2014b; Whipp et al. this volume). This shows that although the methodology used for the underlying physics in this model is a simplified representation, the spatial distribution of faults is consistent with natural datasets and scaled analogue experiments.

The faults developed in the model display a variety of displacement profiles that are related to the degree of interaction between faults. Where faults are isolated and fault tips are unrestricted, symmetrical (e.g. Fault C, Fig. 7b) or triangular profiles 
756 (e.g. Fault D, Fig. 7b) are developed. Profiles representing single-tip restricted (e.g.

757 Fault B, Fig. 7b) and double-tip restricted cases (e.g. Fault A, Fig. 7b) have

758 asymmetric and mesa-style profiles respectively. These profiles are consistent with 759 those interpreted in natural data sets and physical analogue models (e.g. Manighetti 760 et al. 2005; Schlagenhauf et al. 2008, fig. 2; Nixon et al. 2011, Fig. 7; Nixon et al. 761 2014b, Fig. 17; Fossen \& Rotevatn 2016).

\section{Fault growth, propagation and linkage}

During the initial stages of model extension, faults initiate in conjugate orientations throughout the upper brittle crust. With increasing extension these small, isolated faults grow and coalesce into larger faults through along-strike and down-dip linkage (Figs 13-16). One major advantage of the numerical modelling approach is that the three-dimensional distribution of displacement during the growth and linkage process can be assessed. We see multiple transient displacement maxima that continuously migrate as different fault segments progressively interact and link to create the final fault plane. Fossilised examples of this transient behaviour are recorded in nature from the Funan Field, Pattani Basin, Gulf of Thailand, where Kornsawan \& Morley (2002) observed two displacement maxima on a fault plane and inferred this to indicate vertical linkage of two faults in three dimensions. In the model, many of the early displacement maxima associated with initially isolated fault segments are lost by overprinting during the growth and linkage process. For example, initial small fault patches are distributed at various depths in the crust. As these patches propagate laterally and link, the information associated with their nucleation site is removed from the record as displacement maxima migrate each time linkage occurs to the centre of the new, larger fault segment (Figs. 12-15). Capturing evidence for these small displacement features at depth within the crust is difficult when presented with only the final distribution. These observations suggest caution should be used when employing the final displacement-distance distribution, either from displacementdistance (D-x) plots or strike projections of fault displacement, to reconstruct the initial segmentation or the progressive linkage history of a fault. An assumption that the final displacement maximum on a fault plane is coincident with the nucleation point of the fault may be misleading. A further implication of the 3D linkage of 
not be considered representative of the total network, either in spatial distribution and interaction of faults or displacement profiles.

The style of fault initiation and growth developed in the model in the early stages (up to $20 \%$ extension) is consistent with the model of isolated fault growth (Cowie et al. 2000; Schlagenhauf et al. 2008) as opposed to the coherent fault growth model (Walsh et al. 2003b). The observed fault networks develop from fault segments that are initially kinematically independent and propagate radially before linking with adjacent segments to become larger fault zones (Stages 1-3, Fig. 17). In the final stage of the model, however, faults are kinematically linked at depth and there is a heterogeneous distribution of fault activity focussed on the largest faults which is more consistent with the coherent fault growth model (Stage 4, Fig. 17). Examination of fault growth for selected faults at the surface (Figs. $7 \& 8$ ) and the displacement history on strike sections of selected faults (Figs. 13-16) shows that in this final stage, when strain is localising onto the largest faults and relays are being breached, the majority of faults are mainly accruing displacement without further increasing their length. This is consistent with the notion that the two fault growth models are end-members of one system (Fossen \& Rotevatn, 2016), where initially the isolated fault growth model dominates at small strains which is then replaced by the coherent fault growth model at greater strains (Jackson et al., this volume).

\section{Fault network organisation and dip domain development}

Kinematic coherency is maintained in the model by a combination of variation in both the number of active faults and displacement on those faults. Some transects parallel to the extension direction contain many active faults, whereas other have only two or three, but with larger displacements (Fig. 5). This is similar to natural examples, as shown by linkage of the Rangitaiki Fault (Nixon et al. 2014a) and palaeo-earthquake data (Nicol et al. 2010). Analysis of the model evolution, however, highlights the dynamic nature of fault activity across the fault network. Nicol et al. (1997) suggested that the largest faults at the early stages of extension within a network maintain their relative size advantage during rifting and are the largest faults during rift climax. The results documented here suggest this is not necessarily the case. Many of the faults with highest displacement rates during the onset of rifting 
821 (e.g. Stages 1 and 2) do not continue to dominate but may decelerate or become 822 inactive (e.g. Fault C, Figs. 5 \& 6). The largest faults at the end of rifting (i.e. Stage 8234 ) are the ones that are in the most favourable locations with respect to stress 824 interactions during later stages of rifting, which is not necessarily the same as during 825 rift initiation.

826 Observations from natural systems and data from physical analogue experiments 827 indicate that a characteristic feature of rifted fault networks is the occurrence of dip 828 domains within which the dominant fault dip is similar, separated by a rift-wide 829 accommodation zone across which the dominant dip direction changes (e.g. Reches 830 1978; Morley 2002, McClay et al. 2005; Schlagenhauf et al. 2008; Schlische \& 831 Withjack 2009; Healy et al. 2015). Dip domains are a characteristic feature of the 832 fault network developed in this model and are typically of the order of 20-30 km wide. 833 In contrast, dip domain boundaries are narrow regions characterised by interlocking 834 arrays of oppositely dipping faults with slightly overlapping tips (Fig. 4C). In many 835 studies, zones of weakness such as basement lineaments are cited as the control on 836 the location of dip domain boundaries, for example the accommodation zones in the 837 Suez rift (e.g. Patton et al. 1994) and the Northern North Sea rift (e.g. Fossen et al. 838 this volume). However, in the model presented here, dip domains and their 839 boundaries develop spontaneously as a result of the interaction in three-dimensions 840 between evolving conjugate fault sets. There are no pre-existing lineaments or 841 weaknesses controlling the location of dip domain boundaries in this model but they 842 are still present.

\section{CONCLUSIONS}

A three-dimensional discrete element model of fault growth has been used to investigate the nucleation, growth and interaction of normal fault segments and fault network evolution during a single phase of extension. The modelled fault geometry, 848 fault spacing, displacement rates and scaling relationships are consistent with 849 natural examples. In addition, the ability to investigate the evolution of the fault 850 network in three dimensions has demonstrated a number of points that should be 851 taken into consideration when examining the final static fault segment and fault 852 network geometry in outcrop or subsurface (e.g. seismic) datasets. 
853 1. Faults nucleate at minor heterogeneities throughout the brittle, upper crust to 854 form a large number of small faults in conjugate arrangements during the initial $10 \%$ of extension. These initial faults are kinematically isolated and grow by radial propagation.

2. Faults dominantly grow through a combination of tip propagation and linkage of co-linear fault segments to form larger normal faults. Segment linkage occurs progressively with increasing extension and involves linkage between adjacent segments that are located along strike, down dip or oblique to one another. Segment propagation and linkage is inhibited by either the presence of neighbouring faults with an opposing dip, or tip propagation into the stress shadow of a neighbouring, more dominant, fault.

3. The observed style of fault growth is consistent with the isolated fault growth model in the early stages of rifting (before $20 \%$ extension). This is replaced by a style akin to the coherent fault growth model once strain localises onto the largest faults (after 20\% extension in this case). Further increase in fault length is limited by neighbouring faults and dip domain boundaries, at which point the faults continue to accrue displacement without lengthening.

4. Displacement distribution on the faults is highly dynamic, with displacement maxima that continuously migrate as fault segments interact and link to generate the final fault plane. Displacement maxima associated with initially isolated fault segments are generally lost by overprinting during the growth and linkage process. These observations suggest caution when using the final displacementdistance distribution alone to reconstruct either the earliest fault network or the progressive linkage history.

5. Fault scaling statistics for the evolving fault network demonstrate the effect of localisation within the system. Small faults coalesce to become larger faults and the relative importance of small faults in accommodating extensional strain decreases with time. This is achieved by progressive localisation and accelerated displacement rates on larger faults and is not associated with an increase in the applied strain rate.

6. Faults show marked fluctuations in activity related to their relative position within the evolving network and the resultant changes in stress interactions. Faults that dominate the later stages of rifting are those that have optimal locations within 
the late stage fault network. These dominant late-stage faults are not necessarily the faults with highest displacement rates during the early stages of rifting.

7. Dip domains, $20-30 \mathrm{~km}$ wide and comprising faults that have a dominantly similar dip, are a characteristic feature of the fault network developed in the model. Boundaries between dip domains are narrow regions ( $<5 \mathrm{~km}$ wide) characterised by interlocking arrays of oppositely dipping faults with slightly overlapping tips. Dip domains and their boundaries are a natural result of the growth of the fault network and are not related to underlying basement lineaments or heterogeneity.

\section{ACKNOWLEDGEMENTS}

The authors would like to thank Jonny Imber, Martin Schöpfer, Tom Manzocchi and Conrad Childs for constructive comments during the review process and Casey Nixon, Simon Brocklehurst and Julian Mecklenberg for helpful discussions throughout. EF wishes to thank Prof. John McCloskey for insightful comments during development of the code. Thanks also to Eva Bjorseth in Bergen for assistance with figure drafting and Schlumberger for access to Petrel software This contribution forms part of the MultiRift Project funded by the Research Council of Norway's PETROMAKS programme (Project number 215591) and Statoil to the University of Bergen and partners University of Manchester, Imperial College and University of Oslo.

\section{FIGURE CAPTIONS}

Fig. 1. (a) Example of the discrete element media consisting of 1,080,000 elements in a regular hexagonal distribution used to simulate extension in a rift setting. The crust is represented as a two-layer system of brittle (upper crust) and firmoviscous (lower crust) forces. Elements are coloured according to their horizon at the start of the experiment. (b) Sketch of the forces within the upper and lower crust and their rheological response. In the upper crust, the bond fails when a breaking threshold is exceeded. In the lower crust, strain increases when a load is applied. At $t_{1}$ the load is removed and strain reduces slowly over time. (c) View of model from eastern aspect illustrating horizons used in analysis (H52-102) and the viscous response to load in the lower crust (wavy nature of dark grey marker lines).

Fig. 2. (a) Depth of broken bonds in the brittle crust in the experiment at the start of the experiment. (b) Magnitude and direction of displacement $(\mathrm{m})$ for failures shown in (a).

Fig. 3. (a) Oblique three-dimensional view of along-strike complexity relative to elevation for the fault network at $30 \%$ extension relative to initially horizontal beds within the crust (Horizon 52 (H52), Horizon 72 (H72) and Horizon 92 (H92)). Contours on horizons denote $100 \mathrm{~m}$ intervals. The extension direction is towards the north. Displacement on elements that constitute south dipping faults are coloured yellow to red $(2 \mathrm{~km})$ and north dipping faults are coloured pale blue to purple $(2 \mathrm{~km})$. 
Interactions between selected conjugate faults are shown by numbers 1-3. (b) View of the fault network looking east (along-strike). (c) Topography of Horizon 102 at $30 \%$ extension. Contours are at $100 \mathrm{~m}$ intervals, with an elevation range of $1 \mathrm{~km}$ scaled from blue (deep) to orange (high). The extracted fault network is included and marked by dark grey patches. Interaction between conjugate faults marked in (a) are also shown on this surface.

Fig. 4. Map views of Horizon 102 output at increasing extension of $10 \%, 20 \%$ and $30 \%$ to the north. Three regions (A-C) are shown which are used for discussion. (a) Location of faults relative to fault activity and failure time of bonds. (b) Relative topography from blue (minimum) to orange (maximum) overlain with fault locations from (a). $R$ denotes the relief range for each output; $100 \mathrm{~m}$ (10\% extension), $500 \mathrm{~m}$ (20\% extension) and $1 \mathrm{~km}$ (30\% extension). Footwall crests are orange and hangingwall deeps are purple. (c) Dip orientation for faults. South-dipping planes are coloured yellow to red and north-dipping pale to dark blue. Strong colours indicate fault scarps and pale colours between them represent hangingwall and footwall surfaces dipping in the opposite direction. The dominant direction of fault dip shows alignments of both south-dipping faults (red) and north-dipping faults (blue) into dip domains with boundaries indicated by dashed black lines. Black arrows indicate dominant dip directions. Regions $\mathrm{B}$ and $\mathrm{C}$ marked on this figure are referred to later in Figs. 7 \& 8 (Region C) and Figs. 11-16 (Region B).

Fig. 5. (a) Map of fault locations on Horizon 102 at $30 \%$ extension (6 Myr). Dotted vertical lines indicate the location of transects through the data at $6000 \mathrm{~m}$ intervals. Red dots indicate the location of maximum displacement on each transect. Specific faults are coloured to highlight their evolution; Fault B (yellow), Fault C (purple), Fault $D$ (brown), Fault $E$ (blue) and Fault $F$ (green) (b) Evolution of displacement on faults through time along selected transects chosen to highlight the evolution of the fault network and dip domains, numbered 1 to 5 . Bold dashed lines represent faults that show periods of retardation within their history and bold solid lines show growing faults.

Fig. 6. Data for Transects 1-5 from Fig. 5a plotted relative to (a) Percentage strain accommodated by faults against time by north-dipping (open circles) and southdipping faults (closed squares). (b) Polarity plotted against time for the selected transects.

Fig. 7. (a) Map view of Region A highlighted in Fig. 9 through time from $15 \%$ to $30 \%$ extension (3-6 Myr). Traces of Faults A-D are highlighted and correlate to those in Fig. 8a. Number 2 indicates the spill point shown in Fig. 4 in this region. (b) Displacement-distance plots on Faults A-D at the upper surface. Grayscale fill indicates the time of each recording in $1 \mathrm{Myr}$ ( $5 \%$ extension) intervals.

Fig 8. (a) Displacement rate in $1 \mathrm{Myr}$ intervals plotted against distance for Faults A-D from Fig. 7. Selected profiles are marked by vertical lines and coloured with dots. (b) Displacement rate against time for profiles marked along the faults in (a), where colours of inter-section correlate between (a) and (b). 
Fig. 9. Maximum displacement (throw) recorded for selected horizons (H52-102)

969 plotted relative to extension. Intervals between pairs of solid or dashed lines 970 represent $5.0 \%$ extension (1 Myr).

971 Fig. 10. Log-log plot of elapsed time against maximum displacement for the largest 972 thirty faults from the model (stars) plotted relative to data from three offshore and 973 three onshore regions presented in Nicol et al. 1997 (fig. 2). Diagonal lines represent 974 expected fault growth rates. The dotted horizontal line corresponds to 4 Myr.

975 Fig. 11. Three-dimensional views representing seven faults in Region B, Fig. 4. 976 Faults are coloured to aid differentiation and labelled $E$ to K. White arrows indicate 977 the dip direction of faults from their upper surfaces. Dotted white lines indicate 978 intersections between faults. (a) Oblique map view including Horizon 62 with views 979 looking (b) east and (c) west. Views of selected faults from the south (including 980 Horizon 62) with colour-coded displacement on (d) Fault $E$ and (e) Fault $F$. 981 Displacement ranges from purple $(50 \mathrm{~m})$ to red $(2 \mathrm{~km})$. Minor Faults $\mathrm{G}$ to $\mathrm{J}$ are 982 included and dotted white lines demonstrate intersections between faults. The white 983 arrows denote faults dipping towards the viewer.

984 Fig. 12. Map view of elements that constitute faults shown in Fig. 12 relative to depth 985 for (a) Horizon 102, (b) Horizon 92, (c) Horizon 82, (d) Horizon 72, (e) Horizon 62 986 and (f) Horizon 52. Maps are coloured from brown to cream $\pm 750 \mathrm{~m}$ about their 987 respective mean elevation. Footwall crests are cream and hangingwall depocentres 988 are dark brown. Faults $\mathrm{E}$ to $\mathrm{K}$ at each horizon are included as their colour defined in 989 the key (see also Fig. 11). Northern dipping faults are drawn in the immediate 990 hangingwall and southern dipping faults are drawn on the fault crest. The dip 991 direction of fault segments is indicated by white arrows. White circles highlight points 992 of intersection between faults and white stars show fault bifurcation.

993 Fig. 13. Strike projection viewed from the south for Fault $E$ at (a) $15 \%$, (b) $20 \%$, (c) $99425 \%$ and (d) $30 \%$ extension coloured relative to displacement from $50 \mathrm{~m}$ (purple) to $9952 \mathrm{~km}$ (red). Elements coloured grey represent regions where the fault has not, as yet, 996 failed. The fault evolved from six distinct isolated segments (numbered 1-6) into one 997 structure. The location of the change between the upper and lower crust is indicated.

998 Fig. 14. Strike projection viewed from the south for Faults G, H and I at (a) 15\%, (b) $99920 \%$, (c) $25 \%$ and (d) $30 \%$ extension coloured relative to displacement from $50 \mathrm{~m}$ 1000 (purple) to $2 \mathrm{~km}$ (red). Elements coloured grey represent regions where a fault has 1001 not, as yet, failed. The location of the change between the upper and lower crust is 1002 indicated. Gaps between elements indicate where Fault E (Figs. 11 \& 13) intersects 1003 these faults.

1004 Fig. 15. Strike projection viewed from the south for Faults $\mathrm{F}$ and $\mathrm{J}$ which interact as a 1005 conjugate pair at (a) 15\%, (b) 20\%, (c) 25\% and (d) 30\% extension coloured relative 1006 to displacement from $50 \mathrm{~m}$ (purple) to $2 \mathrm{~km}$ (red). Elements coloured grey represent 1007 regions where the fault has not, as yet, failed. Fault $F$ evolved from five distinct 
1008

1009

1010

1011

1012

1013

1014

1015

1016

1017

1018

1019

1020

1021

1022

1023

1024

1025

1026

1027

1028

1029

1030

1031

1032

1033

1034

1035

1036

1037

1038

1039

1040

1041

1042

1043

1044

1045

1046

1047

1048

isolated patches (numbered 7-11) into one fault. The faults interact at the yellow dashed line.

Fig. 16. Maximum displacement recorded in $500 \mathrm{~m}$ vertical swaths for elements that represent a fault versus length. These are extracted at extension increments of $2.5 \%$ from $10 \%$ to $30 \%$ extension for (a) Fault E, (b) Faults G, H and $I$ and (c) Faults $F$ and $\mathrm{J}$. Faults are coloured relative to earlier definitions in Fig. 11. Alternating light and dark patches indicate bands of $2.5 \%$ extension between outputs. Fault segments introduced in Figs. 12 \& 15 are marked for comparison.

Fig. 17. Sketch representation of fault network and fault segment evolution in a schematic basin through four stages. Fault network evolution is shown in relation to a network of conjugate faults dipping towards (black) and away from (grey) the extension direction in three dimensions. The strike projection of fault segment evolution shows an idealised development of a large fault through time from a number of smaller isolated segments at varying depths into a single through-going structure. Its' lateral propagation is constrained at the furthest edge by a conjugate fault that initiates at a similar time dipping in the opposite direction.

Fig. 18. Log-log plots of displacement rate plotted against regional strain following figure 4 of Nicol et al. (1997) to compare with this experiment. The circle represents the mean displacement rate plotted for large faults with displacement $>500 \mathrm{~m}$ in this model with error bars (see Fig. 6).

\section{REFERENCES}

ABE, S., VAN GENT, H. \& URAI, J.L. 2011. DEM simulation of normal faults in cohesive materials. Tectonophysics 512, 12-21.

ACKERMANN, J. \& SCHLISCHE, R.W. 1997. Anticlustering of small normal faults around larger faults. Geology, 25, 12, 1127-1130.

ACKERMANN, R.V., SCHLISCHE, R.W. \& WITHJACK, M.O. 2001. The geometric and statistical evolution of normal fault systems: an experimental study of the effects of mechanical layer thickness on scaling laws. Journal of Structural Geology, 23, 11, 1803-1819.

ACOCELLA, V., FACCENNA, C., FUNICIELLO, R. \& ROSSETTI, F. 1999. Sand-box modelling of basement-controlled transfer zones in extensional domains. Terra Nova, 11, 149-156.

ACOCELLA, V., GUDMUNDSSON, A. \& FUNICIELLO, R., 2000. Interaction and linkage of extension fractures and normal faults: examples from the rift zone of Iceland. Journal of Structural Geology, 22, 1233-1246.

ALLKEN, V., HUISMANS, R.S., FOSSEN, H. \& THIEULOT, C. 2013. 3D numerical modelling of graben interaction and linkage: a case study of the Canyonlands grabens, Utah. Basin Research, 25, 1-14.

BEHN, M.D., LIN, J. \& ZUBER, M.T. 2002. A continuum mechanics model for normal faulting using a strain-rate softening rheology: implications for thermal and 
1049

1050

1051

1052

1053

1054

1055

1056

1057

1058

1059

1060

1061

1062

1063

1064

1065

1066

1067

1068

1069

1070

1071

1072

1073

1074

1075

1076

1077

1078

1079

1080

1081

1082

1083

1084

1085

1086

1087

1088

1089

1090

rheological controls on continental and oceanic rifting. Earth and Planetary Science Letters, 202, 725-740.

BULL, J.M., BARNES, P.M., LAMARCHE, G., SANDERSON, D.J., COWIE, P.A., TAYLOR, S.K. \& DIX, J.K. 2006. High-resolution record of displacement accumulation on an active normal fault: implications for models of slip accumulation during repeated earthquakes. Journal of Structural Geology, 28, 1146-1166.

CAMBORDE, F., MARIOTTI, C. \& DONZÉ, F.V. 2000. Numerical study of rock and concrete behaviour by discrete element modelling. Computers and Geotechnics 27, 225-247.

CARTWRIGHT, J.A., TRUDGILL, B.D. \& MANSFIELD, C.S. 1995. Fault growth by segment linkage: an explanation for scatter in maximum displacement and trace length data from Canyonlands grabens of S.E. Utah. Journal of Structural, 17, 13191326.

CLIFTON, A.E., SCHLISCHE, R.W, WITHJACK, M.O. \& ACKERMANN, R.V., 2000. Influence of rift obliquity on fault-population systematics: results of experimental clay models. Journal of Structural Geology, 22, 1491-1509.

CONNEALLY, J., CHILDS, C. \& WALSH, J.J. 2014. Contrasting origins of breached relay zone geometries. Journal of Structural Geology, 58, 59-68.

CONTRERAS, J., ANDERS, M.H. \& SCHOLZ, C.H. 2000. Growth of a normal fault system: observations from the Lake Malawi basin of the east African rift. Journal of Structural Geology, 22, 159-168.

COWIE, P.A. \& ROBERTS, G.P. 2001. Constraining slip rates and spacings for active normal faults. Journal of Structural Geology, 23, 1901-1915.

COWIE, P.A. \& SCHOLZ, C.H. 1992. Displacement-length scaling relationship for faults: data synthesis and discussion. Journal of Structural Geology, 14, 10, 11491156.

COWIE, P.A., GUPTA, S. \& DAWERS, N.H. 2000. Implications of fault array evolution for synrift depocentre development: insights from a numerical fault growth model. Basin Research, 12, 241-261.

COWIE, P.A., SORNETTE, D \& VANNESTE, C. 1995. Multifractal scaling properties of a growing fault population. Geophysical Journal International, 122,457-469.

COWIE, P.A., UNDERHILL, J.R., BEHN, M.D., LIN, J. \& GILL, C.E. 2005. Spatiotemporal evolution of strain accumulation derived from multi-scale observations of Late Jurassic rifting in the northern North Sea: a critical test of models for lithospheric extension. Earth and Planetary Science Letters, 234, 401-419.

CUNDALL, P.A. 1971. Distinct element models of rock and soil structure. In: Brown, E.T. (Ed.), Analytical and Computational Methods in Engineering Rock Mechanics. Unwin Publishers, London, pp. 129-163.

DAWERS, N. \& ANDERS, M.H. 1995. Displacement-length scaling and fault linkage. Journal of Structural Geology, 17, 2/3, 607-614.

DAWERS, N.H., ANDERS, M.H. \& SCHOLZ, C.H. 1993. Growth of normal faults: Displacement-length scaling. Geology, 21, 1107-1110. 
1091 DONZÉ, F., MAGNIER, S.-A. \& BOUCHEZ, J., 1996. Numerical modelling of a 1092 highly explosive source in an elastic-brittle rock mass. Journal of Geophysical 1093 Research, 101 (2), 3103-3112.

1094 DONZÉ, F., MORA, P. \& MAGNIER, S.-A. 1994. Numerical simulation of faults and 1095 shear zones. Geophysical Journal International 116, 46-52.

1096 DUFFY, O.B., BELL, R.E., JACKSON, C.A.-L., WHIPP, P.S. \& GAWTHORPE, R.L. 1097 2015. Fault growth and interactions in a multiphase rift fault network: Horda Platform, 1098 Norwegian North Sea. Journal of Structural Geology, 80, 99-119.

1099 FAURE WALKER, J.P., ROBERTS, G.P., COWIE, P.A., PAPANIKOLAOU, I.D, 1100 SAMMONDS, P.R., MICHETTI, A.M \& PHILLIPS, R.J. 2009. Horizontal strain rates 1101 and throw-rates across breached relay zones, central Italy: Implications for the preservation of throw deficits at points of normal fault linkage. Journal of Structural Geology, 31, 1145-1160.

FINCH, E., HARDY, S. \& GAWTHORPE, R. 2003. Discrete element modelling of contractional fault-propagation folding above rigid basement blocks. Journal of Structural Geology 25, 515-528.

FINCH, E., HARDY, S. \& GAWTHORPE, R.L. 2004. Discrete element modelling of extensional fault-propagation folding above rigid basement fault blocks. Basin Research 16, 489-506.

FOSSEN, H. \& ROTEVATN, A. 2016. Fault linkage and relay structures in extensional settings - A review. Earth Science Reviews, 154, 14-28.

FOSSEN, H., FAZLI KHANI, H., FALEIDE, J.I., KSIENZYK, A.K. \& DUNLAP, W.J. (this volume) Post-Caledonian extension in the West Norway-northern North Sea region: the role of structural inheritance. In: Childs, C., Holdsworth, R. E., Jackson, C. A.-L., Manzocchi, T., Walsh, J. J. \& Yielding, G. (eds) The Geometry and Growth of Normal Faults, Geological Society, London, Special Publications, 439, http://doi.org/10.1144/SP439.6

GAWTHORPE, R.L., JACKSON, C.A-L., YOUNG, M.J., SHARP, I.R., MOUSTAFA, A.R., AND LEPPARD, C.W. 2003. Normal fault growth, displacement localisation and the evolution of normal fault populations: the Hamman Faraun fault block, Suez Rift, Egypt. Journal of Structural Geology 25, 883-895.

GIBA, M., WALSH, J.J. \& NICOL, A. 2012. Segmentation and growth of an obliquely reactivated normal fault. Journal of Structural Geology, 39, 253-267.

GILLESPIE, P.A., WALSH, J.J. \& WATTERSON, J. 1992. Limitations of dimension and displacement data from single faults and the consequences for data analysis and interpretation. Journal of Structural Geology, 14, 10, 1157-1172.

GROSS, M.R., GUTIÉRREZ-ALONSO, G., BAI, T., WACKER, M.A., COLLINGSWORKTH, K.B. \& BEHL, R.J. 1997.Influence of mechanical stratigraphy and kinematics on fault scaling relations. Journal of Structural Geology, 19, 2, 171183.

GUPTA, S., COWIE, P.A., DAWERS, N.H. \& UNDERHILL, J.R. 2013. A mechanism to explain rift-basin subsidence and stratigraphic patterns through fault-array evolution. Geology, 26, 595-598. 
1134

1135

1136

1137

1138

1139

1140

1141

1142

1143

1144

1145

1146

1147

1148

1149

1150

1151

1152

1153

1154

1155

1156

1157

1158

1159

1160

1161

1162

1163

1164

1165

1166

1167

1168

1169

1170

1171

1172

1173

1174

1175

1176

HARDY, S. \& FINCH, E. 2005. Discrete-element modelling of detachment folding. Basin Research 17: 507-520.

HARDY, S. \& FINCH, E. 2006 Discrete element modelling of the influence of cover strength on basement-involved fault propagation, Tectonophyiscs 415, 225-238.

HARDY, S. \& FINCH, E. 2007. Mechanical stratigraphy and the transition from trishear to kink band fault-propagation fold forms above blind basement faults: A discrete-element study. Marine and Petroleum Geology 24: 75-90.

HARDY, S. 2014. Propagation of blind normal faults to the surface in basaltic sequences: insights from 2D discrete element modelling. Marine and Petroleum Geology, 48, 148-159.

HASSANI, R. \& CHÉRY, J. 1996. Anelasticity explains topography associated with Basin and Range normal faulting. Geology, 24 (12), 1095-1098.

HEALY, D., BLENKINSOP, T.G., TIMMS, N.E., MEREDITH, P.G., MITCHELL, T.M. \& COOK, M.L. 2015. Polymodal faulting: Time for a new angle on shear failure. Journal of Structural Geology, 80, 57-71.

HENZA, A.A., WITHJACK, M.O. \& SCHLISCHE, R.W. 2010. Normal fault development during two phases of non-coaxial extension: An experimental study. Journal of Structural Geology, 32, 1656-1667.

HENZA, A.A., WITHJACK, M.O. \& SCHLISCHE, R.W. 2011. How do the properties of a pre-existing normal-fault population influence fault development during a subsequent phase of extension? Journal of Structural Geology, 33, 1312-1324.

HUGGINS, P., WATTERSON, J., WALSH, J.J. \& CHILDS, C. 1995. Relay zone geometry and displacement transfer between normal faults recorded in coal-mine plans. Journal of Structural Geology, 12, 1741-1755.

HUISMANS, R.S. \& BEAUMONT, C. 2007. Roles of lithospheric strain softening and heterogeneity in determining the geometry of rifts and continental margins. In: Karner, G.D., Manatschal, G \& Pinheiro, L.M. (eds). Imaging, Mapping and Modelling Continental Lithosphere Extension and Breakup. Geological Society London Special Publications, 282, 111-138.

HULL, J. 1988. Thickness-displacement relationship for deformation zones. Journal of Structural Geology, 10, 4, 471-482.

HUS, R., ACOCELLA, V., FUNICIELLO, R. \& De BATIST, M. 2005. Sandbox models of relay ramp structure and evolution. Journal of Structural Geology, 27, 459-473.

IMBER, J, TUCKWELL, G.W., CHILDS, C., WALSH, J.J., MANZOCCHI, T., HEATH, A.E., BONSON, C.G. \& STRAND, J. 2004.Three-dimensional distinct element modelling of relay growth and breaching along normal faults. Journal of Structural Geology 26 (10), 1897-1911.

JACKSON, C. A.-L. \& ROTEVATN, 2013. 3D seismic analysics of the structure and evolution of a salt-influenced normal fault zone: A test of competing fault growth models. Journal of Structural Geology, 54, 215-234.

JACKSON, C. A.-L., BELL, R.E., ROTEVATN, A. \& TVEDT, A.B. 2016. Techniques to determine the kinematics of synsedimentary normal faults and implications of fault growth models. In: Childs, C., Holdsworth, R.E., Jackson, C. A.-L., Manzocchi, T., 
1177 Walsh, J.J. \& Yielding, G. (eds). The Geometry and Growth of Normal Faults.

1178 Geological Society of London Special Publications, 439.

1179 JACKSON, C.A.-L., GAWTHORPE, R.L., LEPPARD \& C.W., SHARP, I.R. 2006. Rift1180 initiation development of normal fault blocks; insights from Hammam Faraun fault 1181 block, Suez Rift, Egypt. Journal of the Geological Society of London 163, 165-183.

1182 KHALIL, S.M. \& McCLAY, K.R. (this volume). 3D geometry and kinematic evolution 1183 of extensional fault-related folds, NW Red Sea, Egypt. In: Childs, C., Holdsworth, R. 1184 E., Jackson, C. A.-L., Manzocchi, T., Walsh, J. J. \& Yielding, G. (eds) The Geometry 1185 and Growth of Normal Faults, Geological Society, London, Special Publications, 439.

1186 KING, G.C.P. \& ELLIS, M. 1990. The origin of large local uplift in extensional 1187 regions. Nature, 348, 689-692.

1188 KING, G.C.P., STEIN, R.S \& RUNDLE, J.B. 1988. The growth of geological 1189 structures by repeated earthquakes 1. Conceptual framework. Journal of 1190 Geophysical Research, 93, 11, 13,307-13,318.

1191 KOMORÓCZI, A., ABE, S. \& URAI, J.L. 2013. Meshless numerical modelling of 1192 brittle-viscous deformation: first results on boudinage and hydrofracturing using a 1193 coupling of discrete element method (DEM) and smoothed particle hydrodynamics 1194 (SPH). Computers and Geosciences, 17, 373-390.

1195 KORNSAWAN, A \& MORLEY, C.K. 2002. The origin and evolution of complex 1196 transfer zones (graben shifts) in conjugate fault systems around the Funan Field, 1197 Pattani Basin, Gulf of Thailand. Journal of Structural Geology, 24, 435-449.

1198 KUHN, M.R. 1999. Structured deformation in granular materials. Mechanics of 1199 Materials 31, 407-429.

1200 KUSZNIR, N.J. \& PARK, R.G. (1987). The extensional strength of the continental 1201 lithosphere: its dependence on geothermal gradient, crustal composition and 1202 thickness. In: Coward, M.P., Dewey, J.F. \& P.L. Hancock (eds). Continental 1203 Extensional Tectonics, Geological Society of London Special Publication, 28, 35-52.

1204 LAMBERT, C. \& COLL, C. 2014. Discrete modelling of rock joints with a smooth-joint 1205 contact model. Journal of Rock Mechanics and Geotechnical Engineering, 6, 1-12.

1206 LONG, J.J. \& IMBER, J. 2011. Geological controls on fault relay zone scaling. 1207 Journal of Structural Geology, 33 (12), 1790-1800.

1208 LONG, J.J. \& IMBER, J. 2012. Strain compatibility and fault linkage in relay zones on 1209 normal faults. Journal of Structural Geology, 36, 16-26.

1210 LONGSHAW, S.M., TURNER, M.J., FINCH, E. \& GAWTHORPE, R.L. 2009. 1211 Discrete element modelling using a parallelised physics engine. In: International 1212 Conference on Particle-Based Methods-Fundamentals and Applications, Particles 1213 2009, 344-347.

1214 LOVELY, P., FLODIN, E., GUZOFSKI, C., MAERTEN, F. \& POLLARD, D.D. 2012. 1215 Pitfalls among the promises of mechanics-based restoration: Addressing implications 1216 of unphysical boundary conditions. Journal of Structural Geology, 41, 47-63.

1217 MANGHETTI, I., CAMPILlO, M., SAMMIS, C., MAI, P.M. \& KING, G. 2005. 1218 Evidence for self-similar slip distributions on earthquakes: Implications for 1219 earthquake fault mechanics. Journal of Geophysical Research, 110, B05302, 1220 doi:10.1029/2004JB003217. 
MANIGHETTI, I., CAMPILLO, M., BOULEY, S. \& COTTON, F. 2007. Earthquake scaling, fault segmentation, and structural maturity. Earth and Planetary Science Letters, 253, 429-438.

MARRETT, R \& ALLMENDINGER, R.W. 1990. Kinematic analysis of fault-slip data. Journal of Structural Geology, 12, 8, 973-986.

McCLAY, K.R., DOOLEY, T., WHITEHOUSE, P. \& MILLS. M. 2002. 4-D evolution of rift systems: Insights from scaled physical models. AAPG Bulletin, 86 (6), 935-959.

McCLAY, K.R., DOOLEY, T., WHITEHOUSE, P.S. \& ANADON-RUIZ, S. 2005. 4D analogue models of extensional fault systems in asymmetric rifts: $3 \mathrm{D}$ visualisation and comparisons with natural examples. In: Doré, A.G. \& Vinning, B.A. (eds). Petroleum Geology: North West Europe and Global Perspectives -Proceedings of the $6^{\text {th }}$ Petroleum Geology Conference, 1543-1556.

McLEOD, A.E., DAWERS, N.H. \& UNDERHILL, J.R. 2000. The propagation and linkage of normal faults: insights from the Strathspey-Brent-Statfjord fault array, northern North Sea. Basin Research, 12, 263-284.

MORA, P. \& PLACE, D. 1993. A lattice solid model for the non-linear dynamics of earthquakes. International Journal of Modern Physics C4, 1059-1074.

MORA, P. \& PLACE, D. 1994. Simulation of the frictional stick-slip instability. Pure and Applied Geophysics 143, 61-87.

MORIYA, S., CHILDS, C., MANZOCCHI, T. \& WALSH, J.J. 2005. Analysis of the relationship between strain, polarity and population slope for normal fault systems. Journal of Structural Geology, 27, 1113-1127.

MORLEY, C.K. 2002. Evolution of large normal faults: Evidence from seismic reflection data. AAPG Bulletin, 86 (6), 961-978.

MORLEY, C.K., GABDI, S. \& SEUSUTTHIYA, S.G.K. 2007. Fault superimposition and linkage resulting from stress changes during rifting: Examples from 3D seismic data, Phitsanulok Basin, Thailand. Journal of Structural Geology, 29, 646-663.

NICOL, A., WALSH, J.J, WATTERSON, J. \& CHILDS, C. 1996. The shapes, major axis orientations and displacement patterns of fault surfaces. Journal of Structural Geology, 18, 2/3, 235-248.

NICOL, A., WALSH, J.J., VILLAMOR, P., SEEBECK, H. \& BERRYMAN, K.R. 2010. Normal fault interactions, paleoearthquakes and growth in an active rift. Journal of Structural Geology, 32, 1101-1113.

NICOL, A., WALSH, J.J., WATTERSON, J \& UNDERHILL, J.R. 1997. Displacement rates of normal faults. Nature, 390, 157-159.

NIXON, C.W., SANDERSON, D.J. \& BULL, J.M. 2011. Deformation within a strikeslip fault network at Westward Ho!, Devon, U.K.: Domino vs conjugate faulting. Journal of Structural Geology, 33, 833-843.

NIXON, C.W, BULL, J.M \& SANDERSON, D.J. 2014a. Localised vs distributed deformation associated with the linkage history on an active normal fault, Whakatan Graben, New Zealand. Journal of Structural Geology, 69, 266-280.

NIXON, C.W., SANDERSON, D.J., DEE, S.J., BULL, J.M., HUMPHREYS, R.J. \& SWANSON, M.H. 2014b. Fault interactions and reactivation within a normal-fault network at Milne Point, Alaska. AAPG Bulletin, 98 (10), 2081-2107. 
1265 PATTON, T.L., MOUSTAFA, A.R., NELSON, R.A. \& ABDINE, A.S. 1994. Tectonic 1266 evolution and structural setting of the Gulf of Suez Rift. In: Landon, S.M. (ed.) Interior 1267 Rift Basins. American Association of Petroleum Geologists Memoir, 59, 9-55.

1268 PEACOCK, D.C.P. \& SANDERSON, D.J. 1991. Displacement, segment linkage and 1269 relay ramps in normal fault zones, Journal of Sedimentary Geology, 15, 721-733.

1270 PLACE, D. \& MORA, P. 2001. A random lattice solid model for simulation of fault 1271

1272

1273 zone dynamics and fracture processes. In: H.-B., Dyskin, A.V., Pasternak, E. (eds.), Bifurcation and Localisation Theory for Soils and Rocks '99, Mulhaus, , A.A. Balkema, Rotterdam/Brookfield.

1274 PLACE, D., LOMBARD, F., MORA, P. \& ABE, S. 2002. Simulation of the 1275 Microphysics of rocks using LSM Earth. Pure and Applied Geophysics 159, 191112761932.

1277 POTYONDY, D.O. \& CUNDALL, P.A. 2004. A bonded-particle model for rock. 1278 International Journal for Rock Mechanics and Mining, 41, 1329-1364.

1279 RANALLI, G. 1995. Rheology of the Earth (2 ${ }^{\text {nd }}$ edition). Chapman and Hall, London.

1280 RECHES, Z. 1978. Analysis of faulting in three-dimensional strain field. 1281 Tectonophysics, 47, 109-129.

1282 REEVE, M.T., BELL, R.E., DUFFY, O.B., JACKSON, C.A.-L. \& SANSOM, E. 2015. 1283 The growth of non-colinear normal fault systems; What can we learn from 3D 1284 seismic reflection data? Journal of Structural Geology, 70, 141-155.

SCHLAGENHAUF, A., MANGHETTI, I., MALAVIEILLE, J. \& DOMINGUEZ, S. 2008. Incremental growth of normal faults: Insights from a laser-equipped analog experiment. Earth and Planetary Science Letters, 273, 299-311.

SCHLISCHE, R.W. \& WITHJACK, M.O. 2009. Origin of fault domains and faultdomain boundaries (transfer zones and accommodation zones) in extensional provinces: Result of random nucleation and self-organised growth. Journal of Structural Geology, 31, 910-925.

SCHÖPFER, M.P.J., CHILDS, C., \& WALSH, J.J. 2007a. 2D distinct element modeling of the structure and growth of normal faults in a multilayer sequence. Part 1: Model calibration, boundary conditions and selected results. Journal of Geophysical Research 112, B10401.

SCHÖPFER, M.P.J., CHILDS, C., \& WALSH, J.J. 2007b. 2D distinct element modeling of the structure and growth of normal faults in a multilayer sequence. Part 2: Impact of confining pressure and strength contrast on fault zone geometry and growth. Journal of Geophysical Research 112, B10404.

SCHÖPFER, M.P.J., ABE, S., CHILDS, C. \& WALSH, J.J. 2009. The impact of crack and density on elasticity, strength and friction of cohesive granular materials: Insights from DEM modelling. International Journal of Rock Mechanics and Mining Science 46, 250-261.

SCHÖPFER, M.P.J., ARSLAN, A., WALSH, J.J. \& CHILDS, C. 2011, Reconciliation of contrasting theories for fracture spacing in layered rocks. Journal of Structural Geology 33: 551-565.

SHARP, I.R., GAWTHORPE, R.L., UNDERHILL, J.R., \& GUPTA, S. 2000. Fault propagation folding and extensional settings: Examples of structural style and synrift 
1309

1310

1311

1312

1313

1314

1315

1316

1317

1318

1319

1320

1321

1322

1323

1324

1325

1326

1327

1328

1329

1330

1331

1332

1333

1334

1335

1336

1337

1338

1339

1340

1341

1342

1343

1344

1345

1346

1347

1348

1349

1350

1351

1352

sedimentary response from the Suez rift, Sinai, Egypt. Bulletin Geological Society of America 112, 1877-1899.

SOLIVA, R., BENEDICTO, A., SCHULTZ, R.A., MAERTEN, L. \& MICARELLI, L. 2008. Displacement and interaction of normal fault segments branched at depth: Implications for fault growth and potential earthquake rupture size. Journal of Structural Geology, 30, 1288-1299.

SPENCE, G. H. \& FINCH, E. 2014. Influences of nodular chert rhythmites on natural fracture networks in carbonates: an outcrop and two-dimensional discrete element modelling study. In: Spence G. H., Redfern J., Aguilera R., Bevan T. G., Cosgrove J. W., Couples G. D., Daniel J.-M. (eds). Advances in the Study of Fractured Reservoirs, Geological Society, London, Special Publications. 374, 211-249.

TOOMEY, A., BEAN, C.J. 2000. Numerical simulation of seismic waves using a discrete particle scheme. Geophysical Journal International 141, 595-604.

TORABI, A. \& BERG, S.S. 2011. Scaling of fault attributes: A review. Marine and Petroleum Geology, 28, 1444-1460.

WALSH J.J. et al. 2001. Geometric controls on the evolution of normal fault systems. In: Holdsworth, R.E., Strachan, R.A., MAGLOUGHLIN, J.F. \& KNIPE, R.J. (eds). The Nature and Tectonic Significance of Fault Zone Weakening. Geological Society, London, Special Publications, 186, 157-169.

WALSH, J.J., CHILDS, C., IMBER, J., MANZOCCHI, T., WATTERSON, J. \& NELL, P.A.R. 2003a. Strain localisation and population changes during fault system growth within the Inner Moray Firth, Northern North Sea. Journal of Structural Geology, 25, 307-315.

WALSH, J.J., BAILEY, W.R., CHILDS, C., NICOL, A. \& BONSON, C.G. 2003b. Formation of segmented normal faults: a 3-D perspective. Journal of Structural Geology, 25, 1251-1262.

WANG, Y. \& MORA, P. 2008. Macroscopic properties of regular lattices. Journal of Mechanics and Physics of Solids, 56, 3459-3474.

WENK, L. \& HUHN, K. 2013. The influence of an embedded viscoelastic-plastic layer on kinematics and mass transport pattern within accretionary wedges. Tectonophysics, 608, 653-666.

WHIPP, P.S., JACKSON, C. A.-L., SCHLISCHE, R.W., WITHJACK, M.O. \& GAWTHORPE, R.L. (this volume). Spatial distribution and evolution of fault-segment boundary types in rift systems: observations from experimental clay models. In: Childs, C., Holdsworth, R. E., Jackson, C. A.-L., Manzocchi, T., Walsh, J. J. \& Yielding, G. (eds) The Geometry and Growth of Normal Faults, Geological Society, London, Special Publications, 439.

WOJTAL, S.F. 1996. Changes in fault displacement populations correlated to linkage between faults. Journal of Structural Geology, 18, 2/3, 265-279.

WRIGHT, T.M. et al., 2012. Geophysical constraints on the dynamics of spreading centres from rifting episodes on land. Nature Geoscience, 5, 242-250.

WU, J.E., McCLAY, K. \& FRANKOWICZ, E. 2015. Niger Delta gravity-driven deformation above the relict Chain and Charcot oceanic fracture zones, Gulf of Guinea: Insights from analogue models. Marine \& Petroleum Geology, 65, 43-62. 
1353 XU, S.-S., NIETO-SAMANIEGO, A.F. \& ALANIZ-ÁLVAREZ, S.A. 2014. Estimation of 1354 average to maximum displacement ratio by using fault displacement-distance 1355 profiles. Tectonophysics, 636, 190-200.

1356 YIELDING, G., NEEDHAM, T \& JONES, H. 1996. Sampling of fault populations 1357 using sub-surface data: a review. Journal of Structural Geology,18, 2/3, 135-146.

1358 YIELDING, G., WALSH, J. \& WATTERSON, J. 1992. The prediction of small-scale 1359 faulting in reservoirs. First Break, 10, 12, 449-460.

1360 YOUNG, M.J., GAWTHORPE, R.L., AND \& HARDY, S. 2001. Growth and linkage of 1361 a segmented normal fault zone; the late Jurassic Murchison-Statfjord North Fault, 1362 northern North Sea. Journal of Structural Geology 23(12), 1933-1952. 


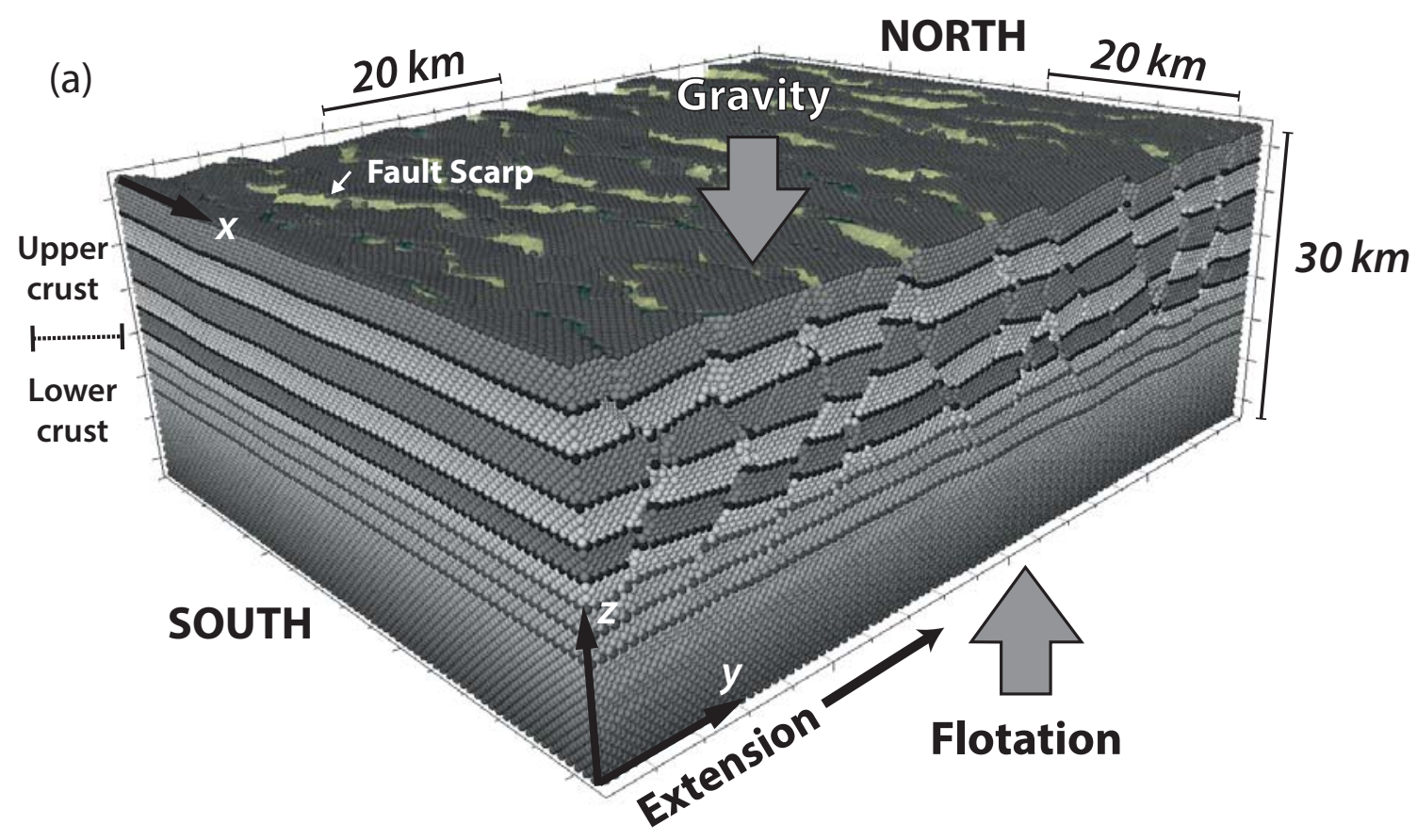

(b)
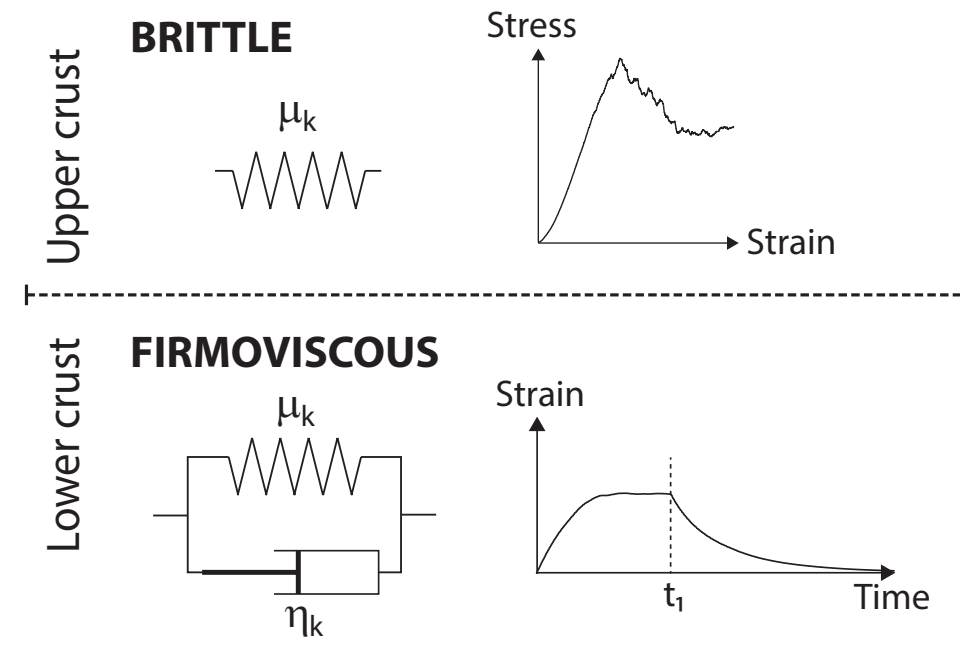

(c)

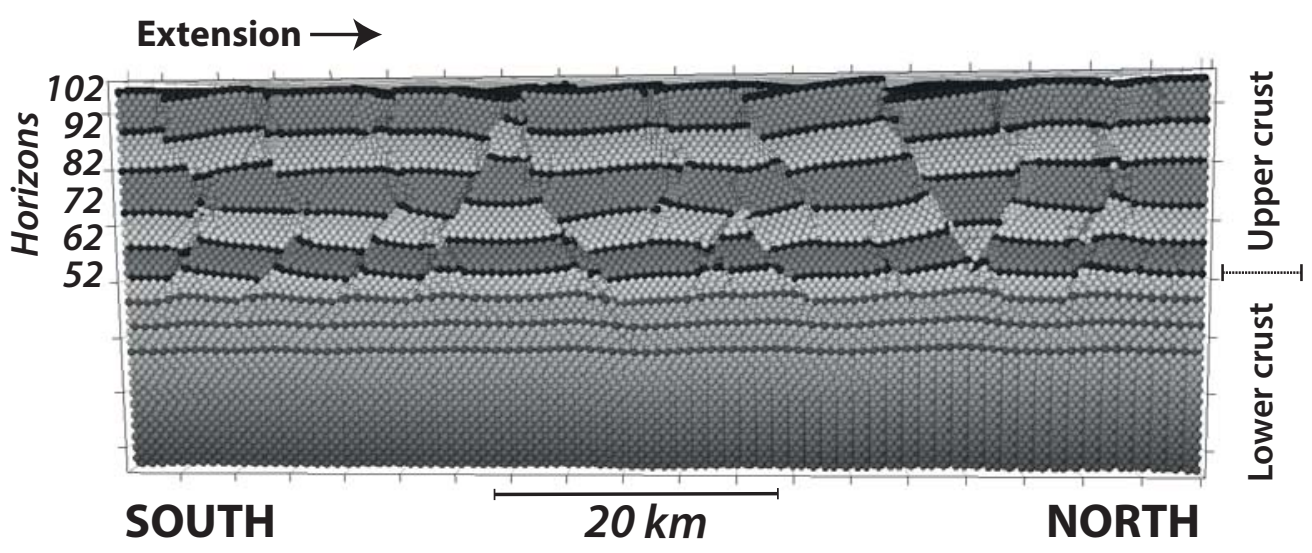

Fig. 1 
(a)
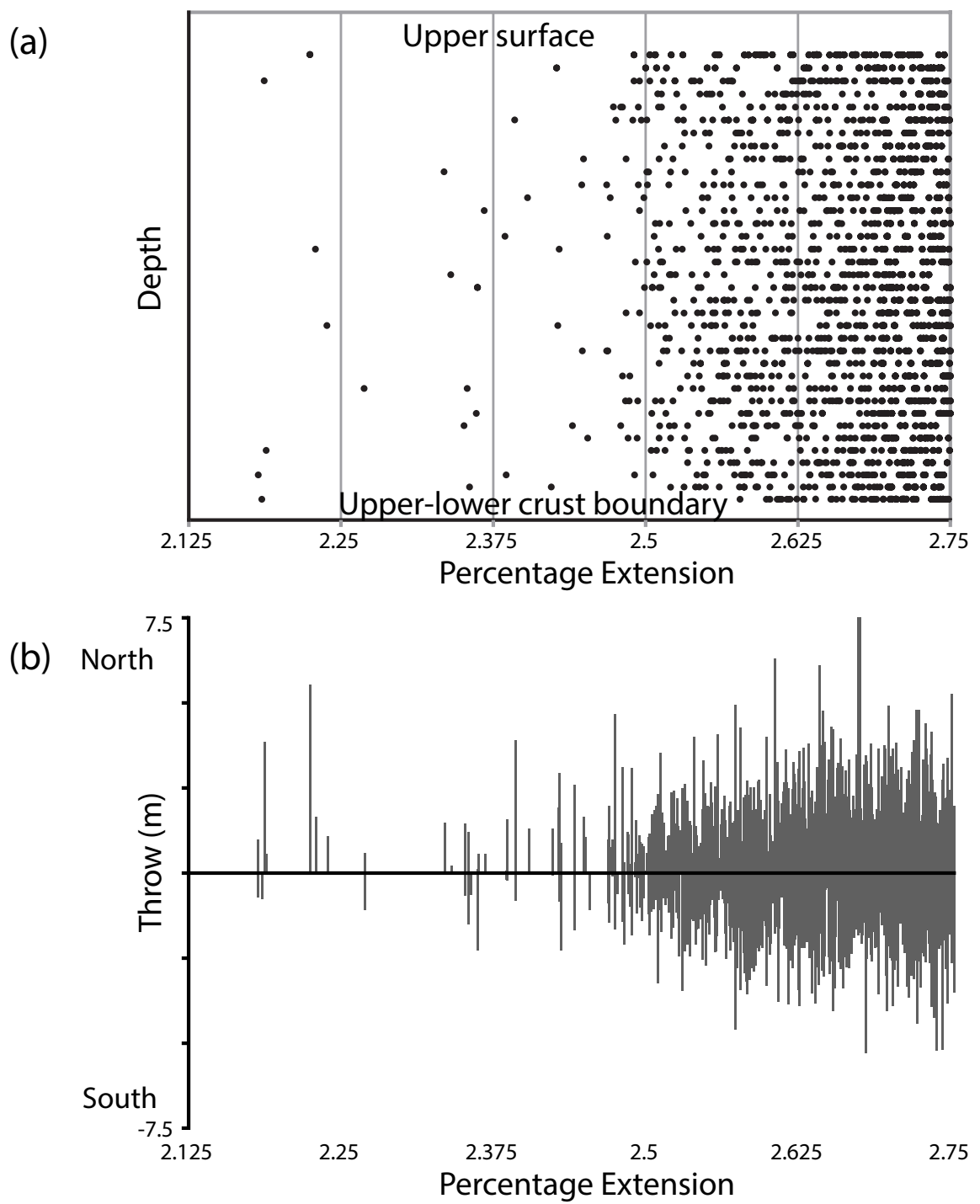

Fig. 2 

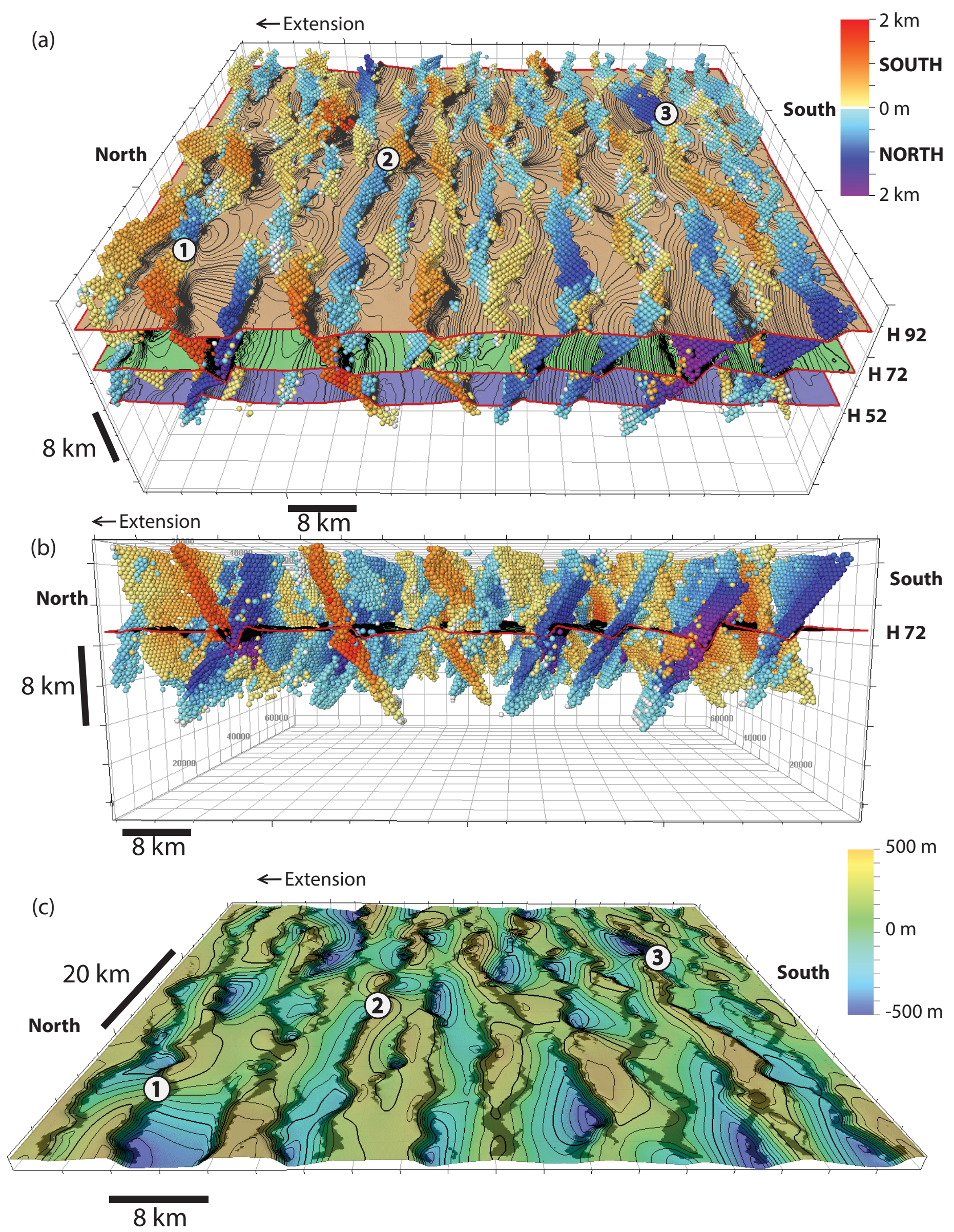

Fig. 3 
North
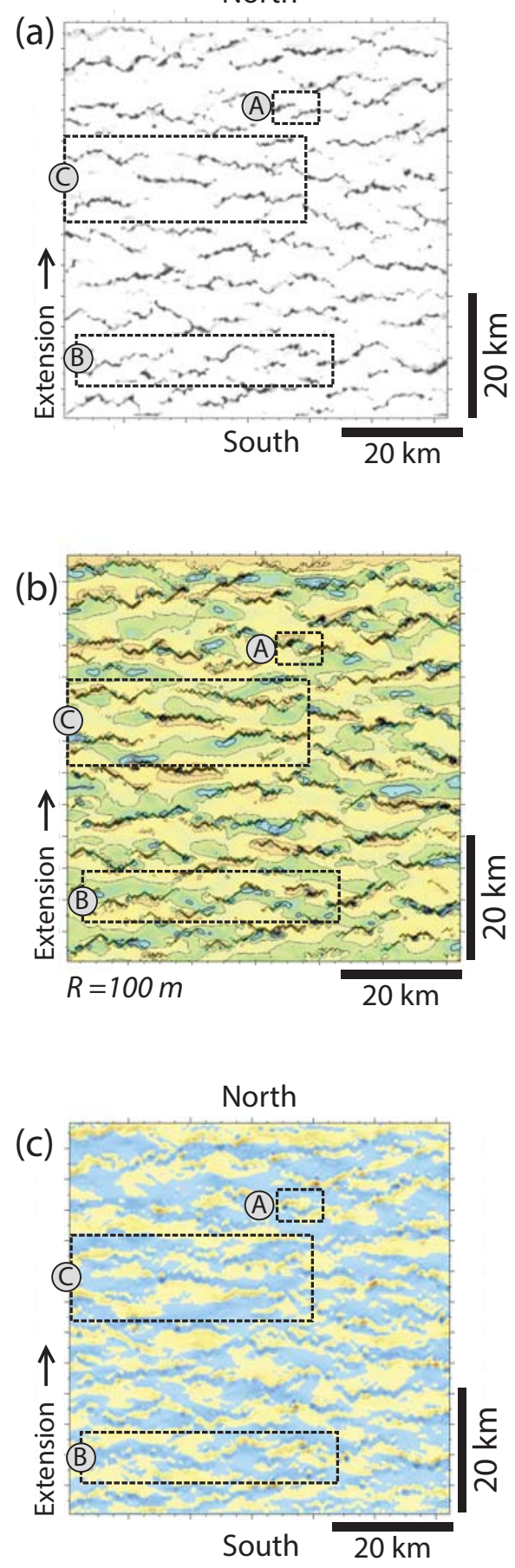
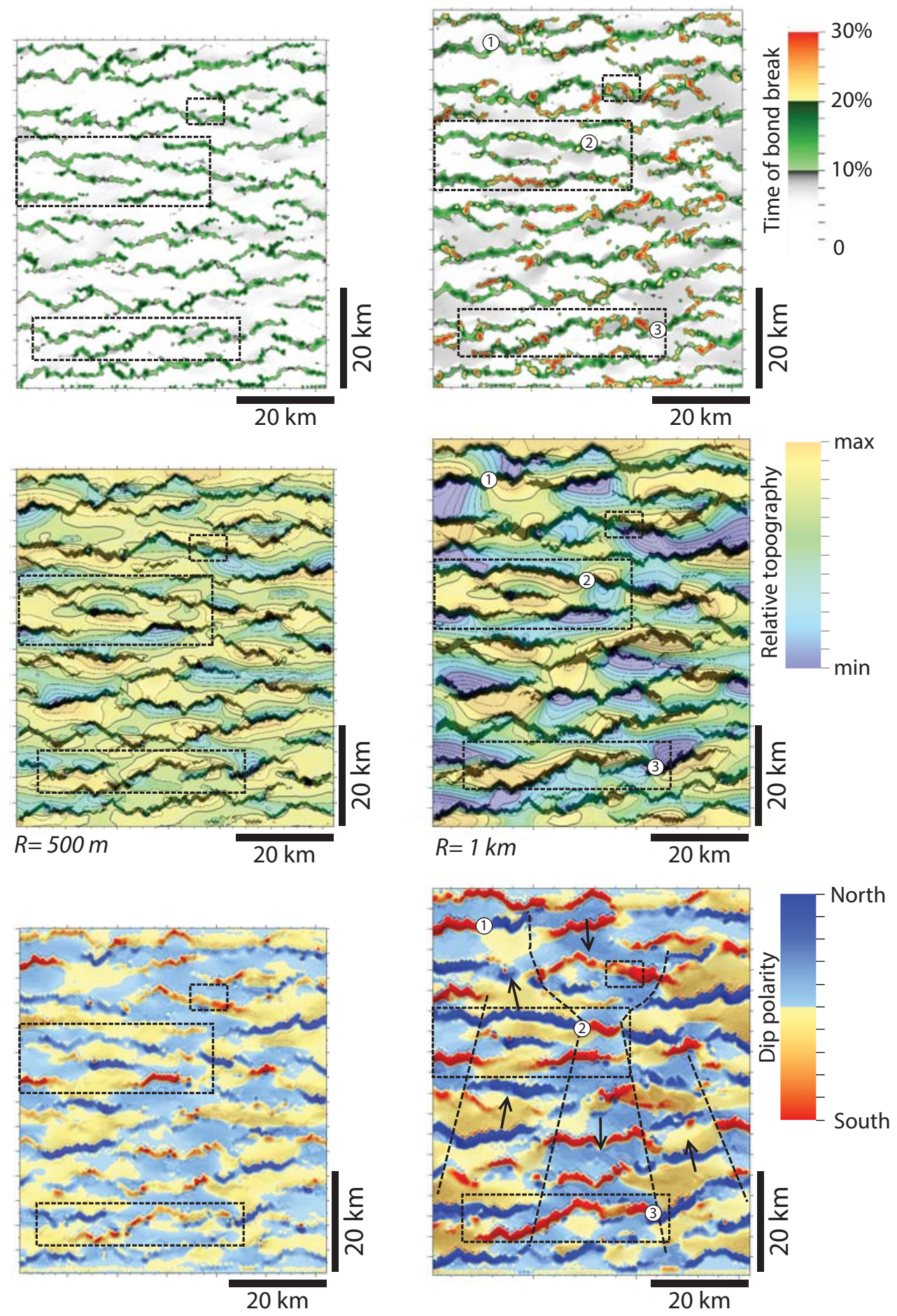

Fig. 4 


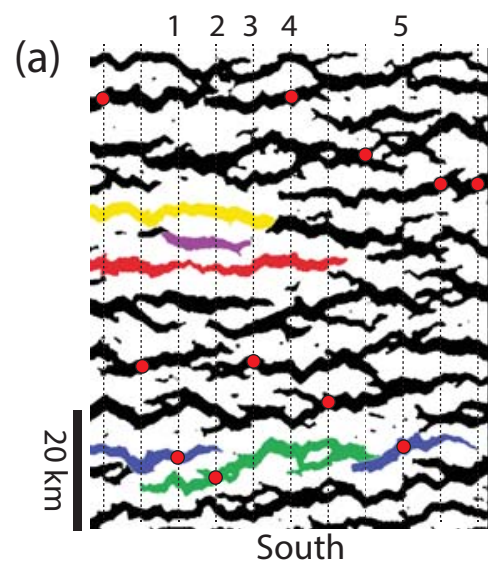

(b)
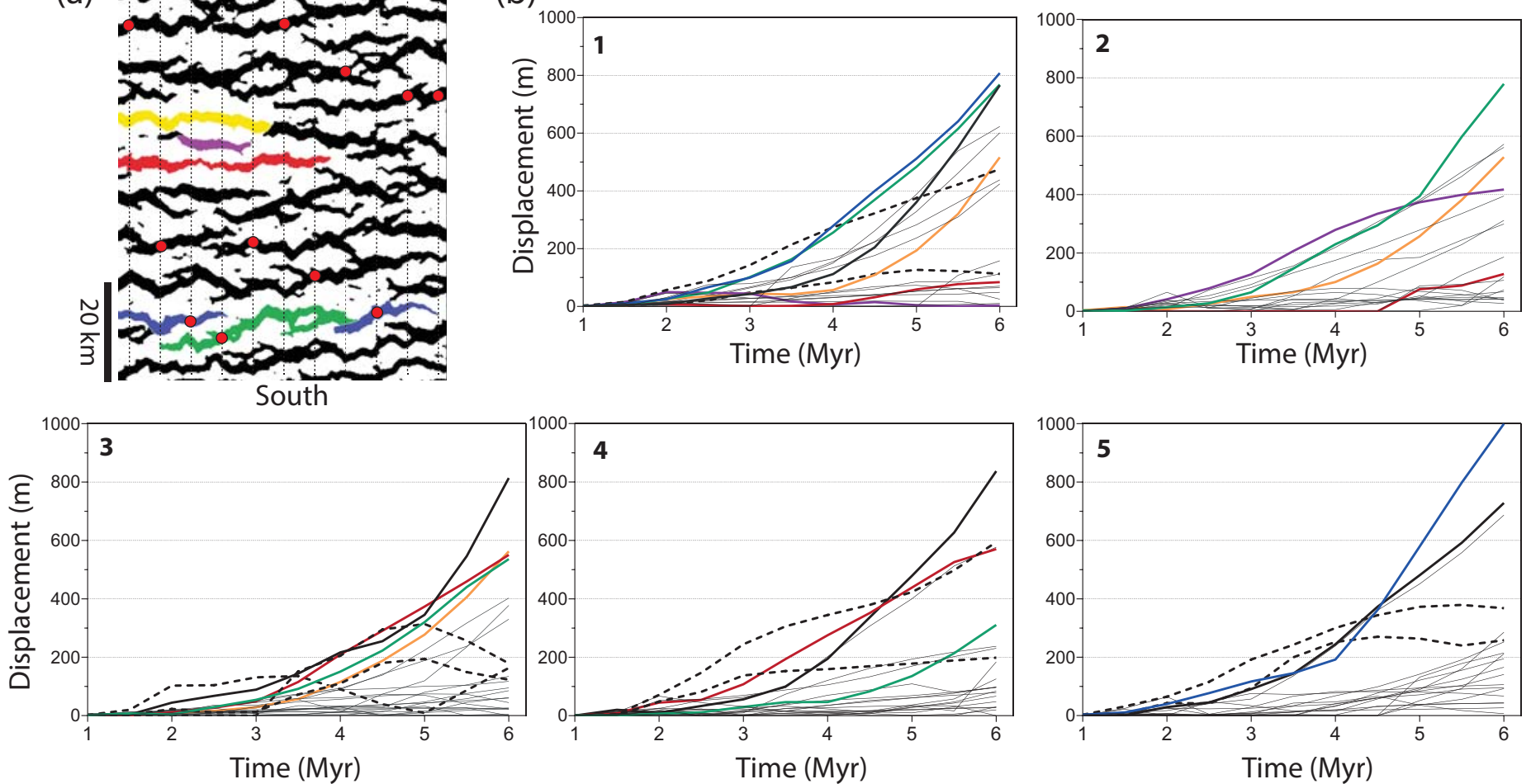

Fig. 5 
(a)
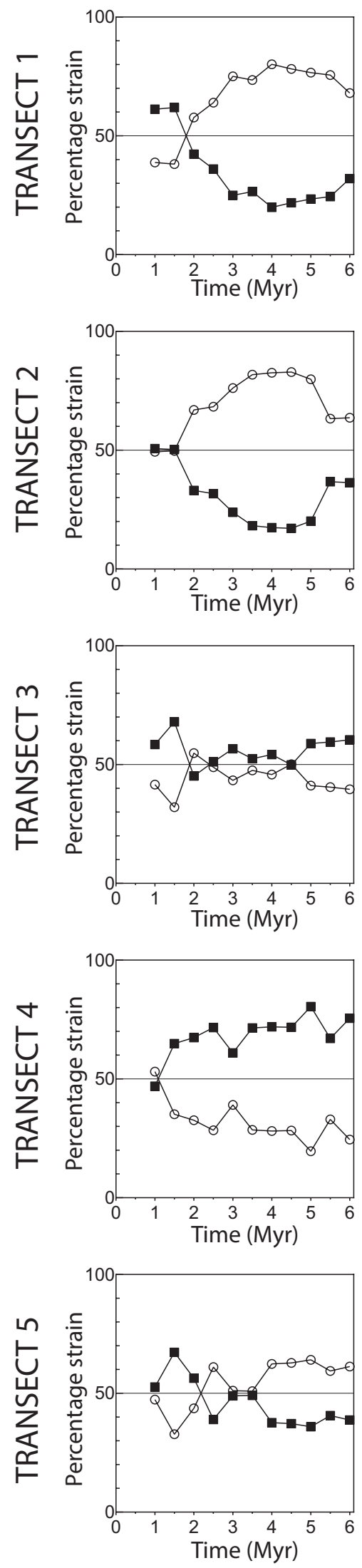

(b)
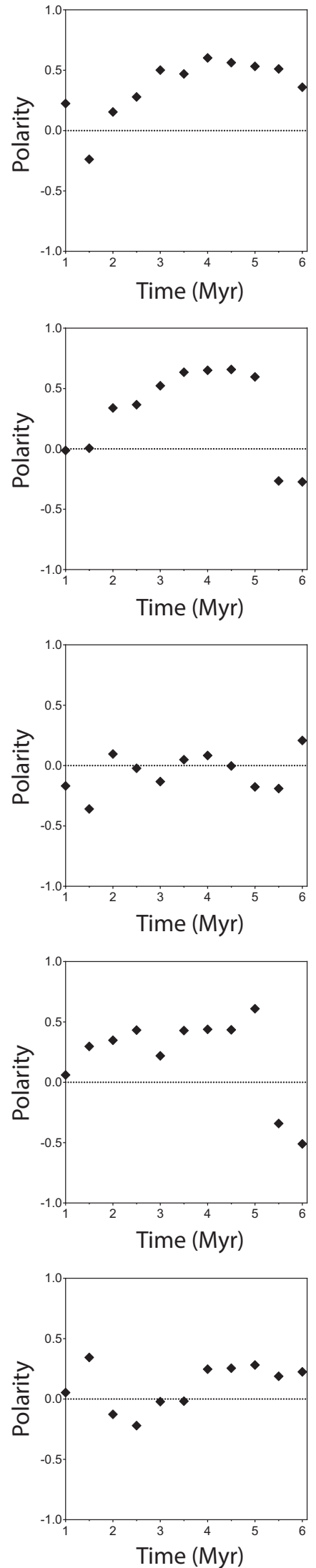

Fig. 6 
(a)
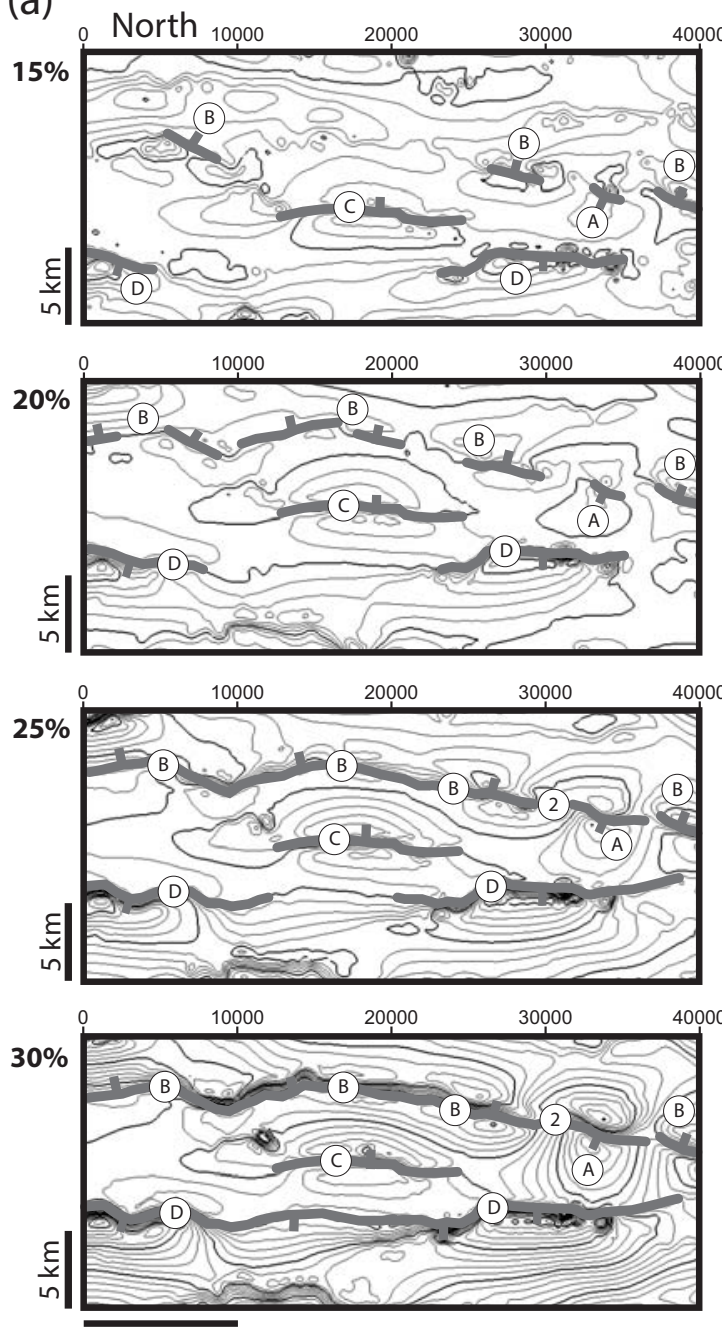

$10 \mathrm{~km}$ (b)
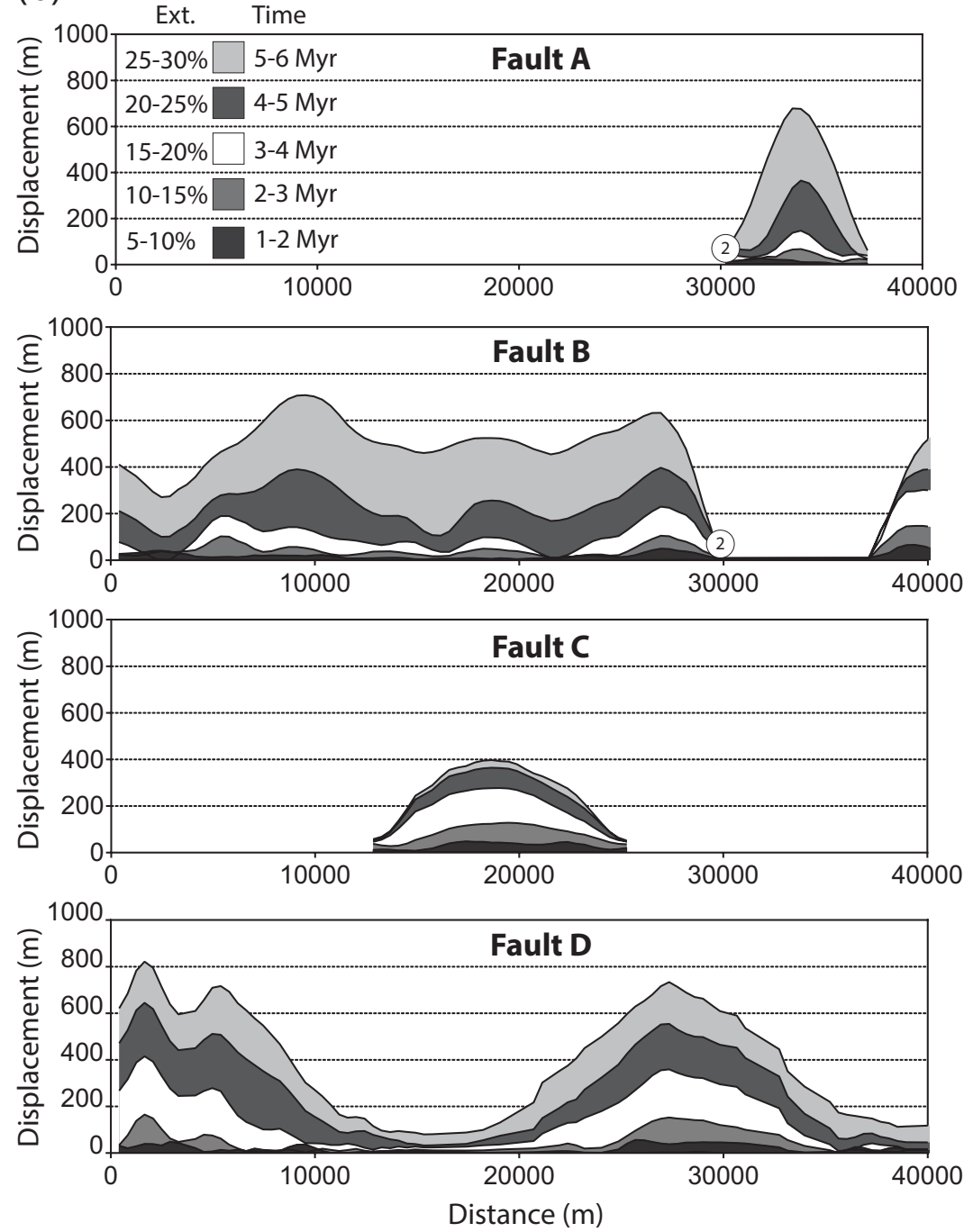

Fig. 7 
(a)

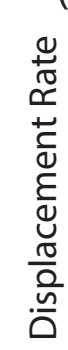

峁

0.4

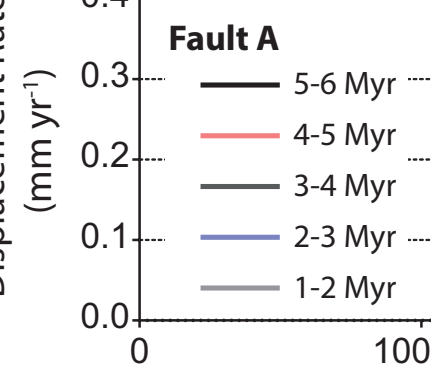

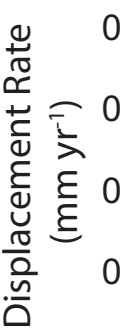
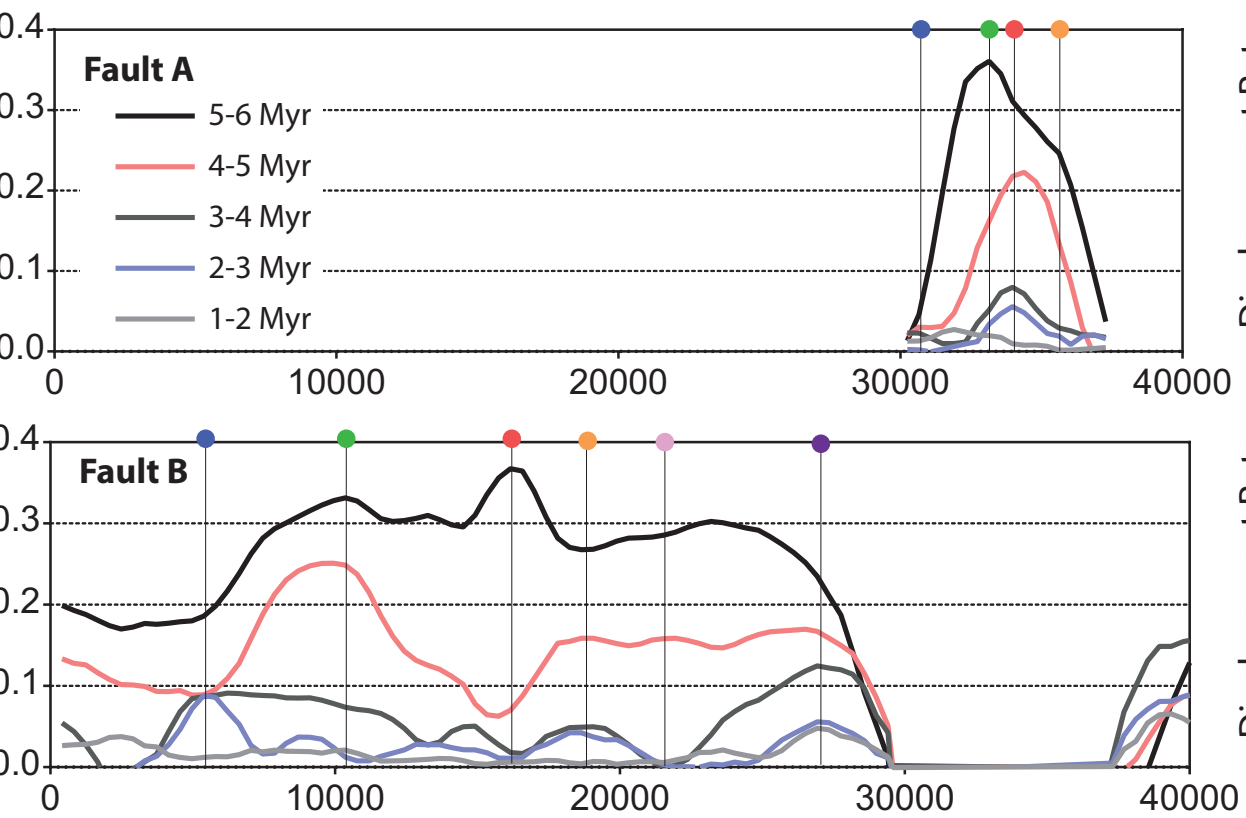

(b)
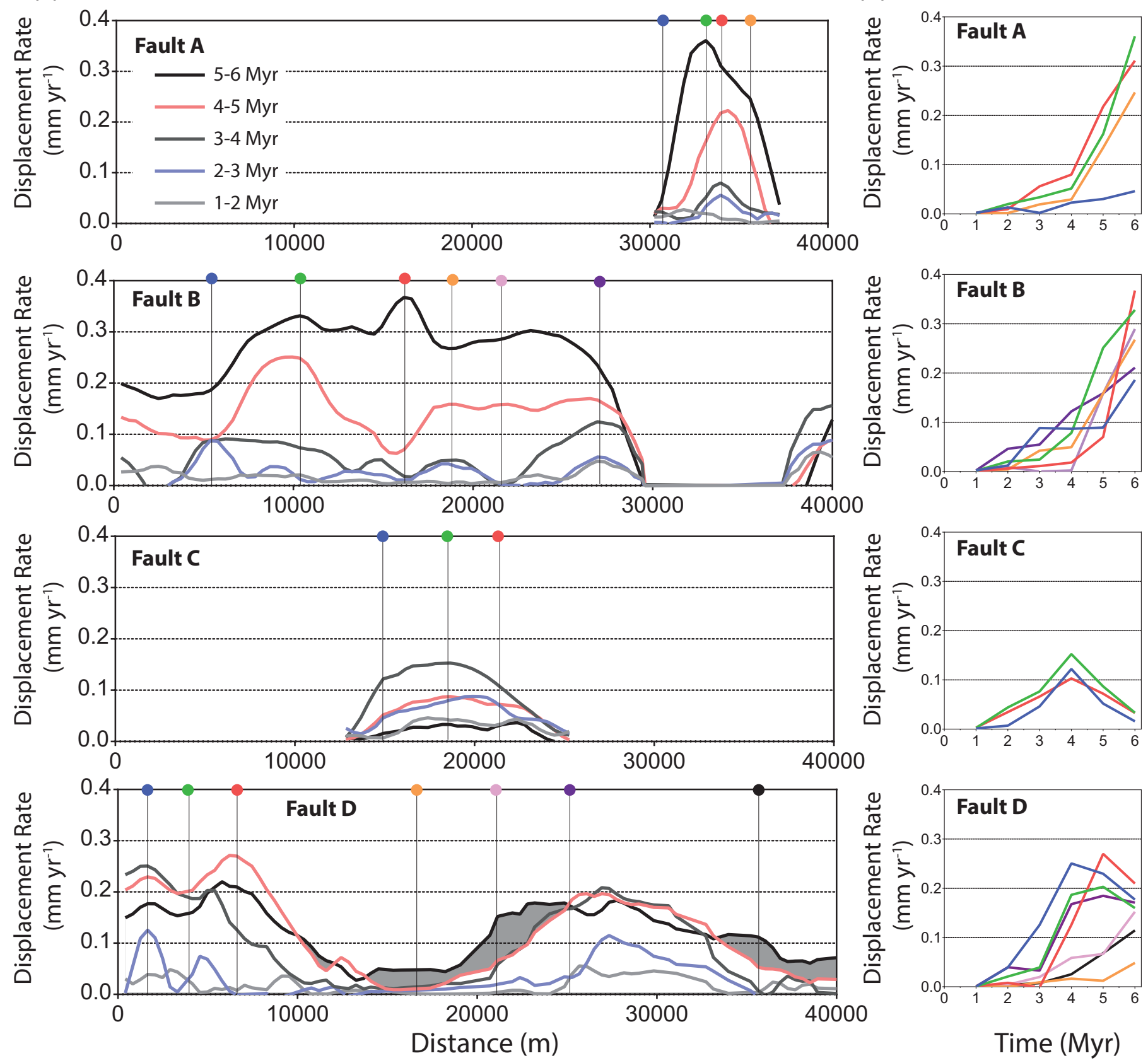

Fig. 8 


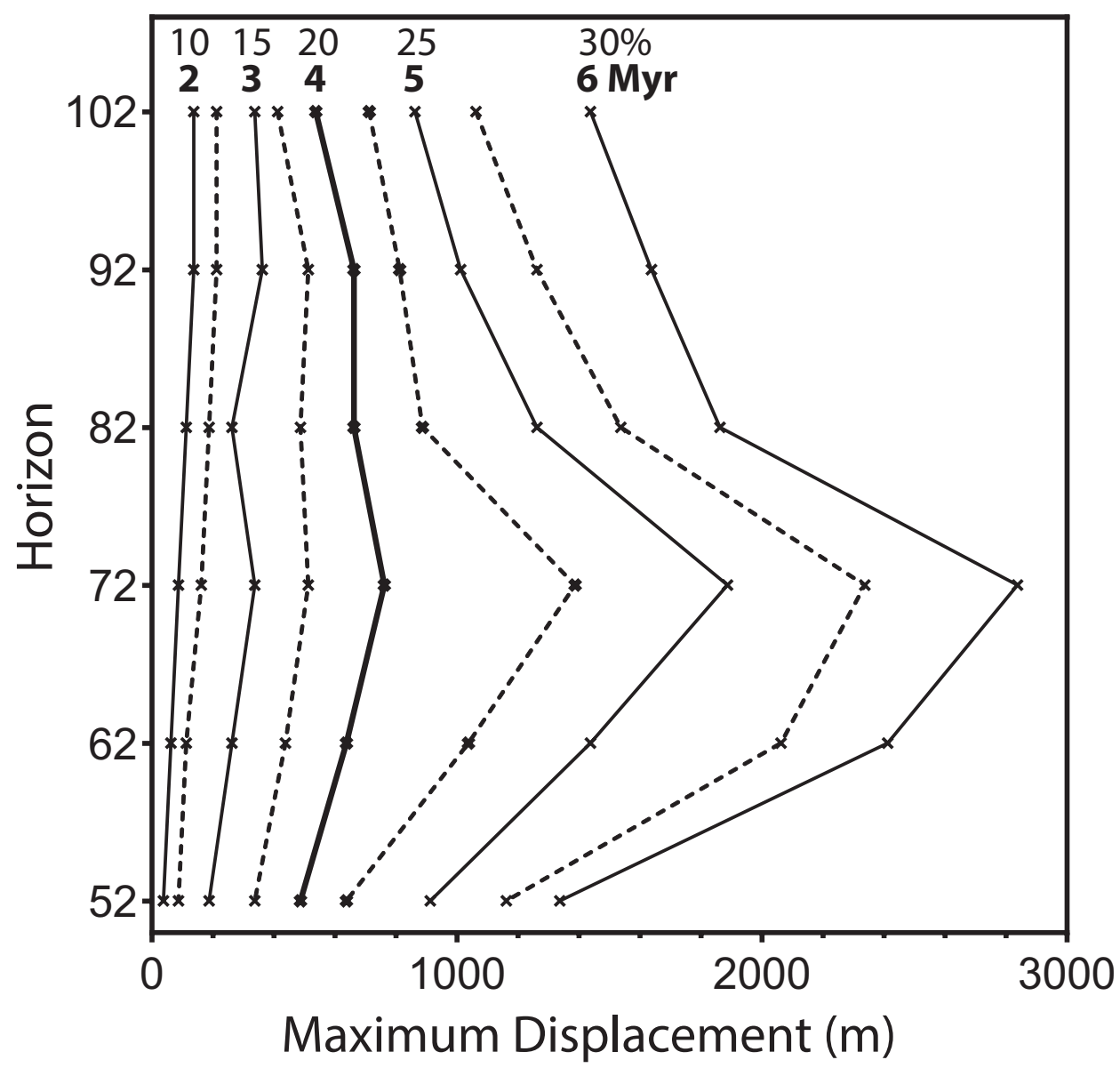

Fig. 9 


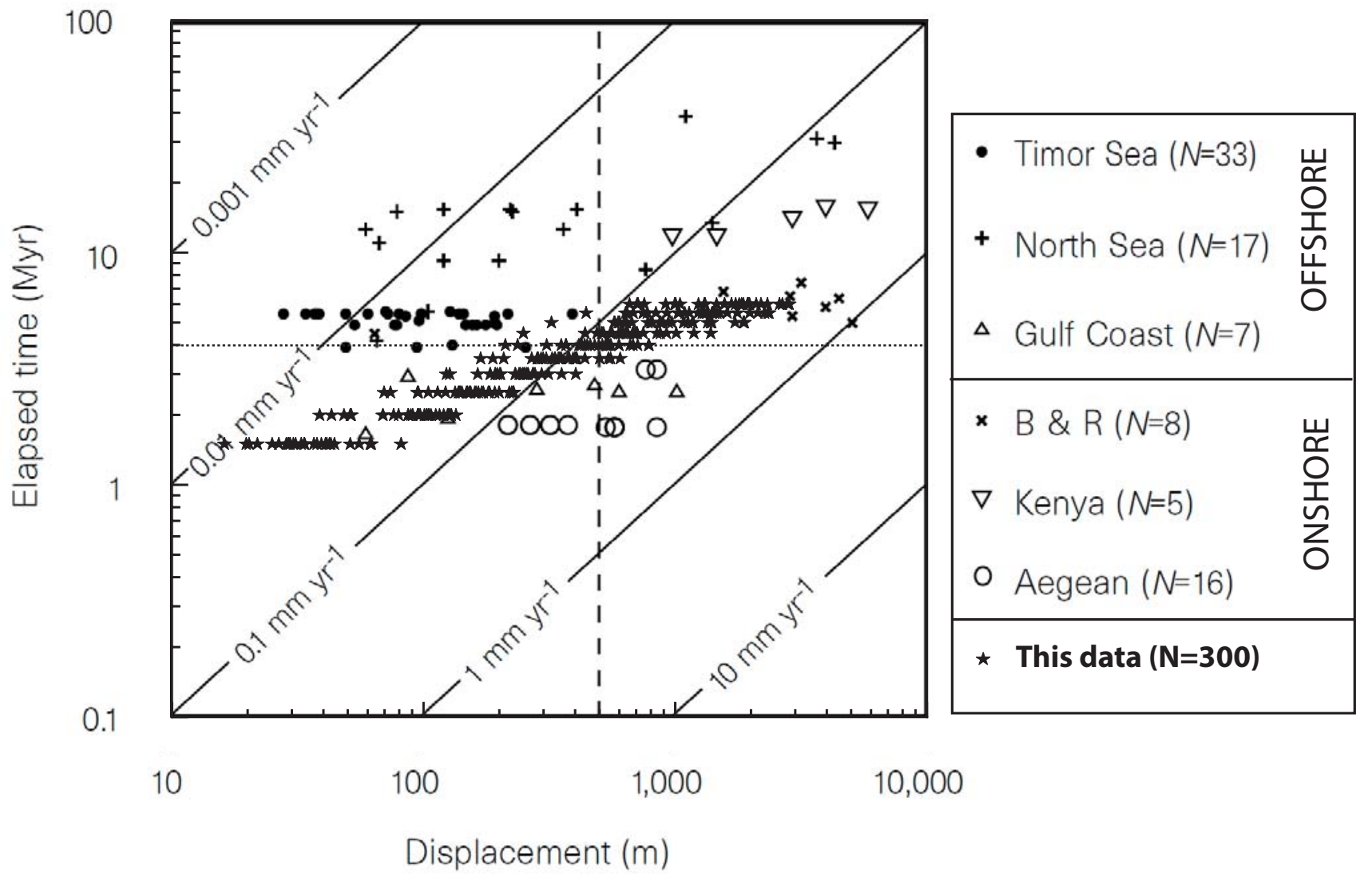

Fig. 10 

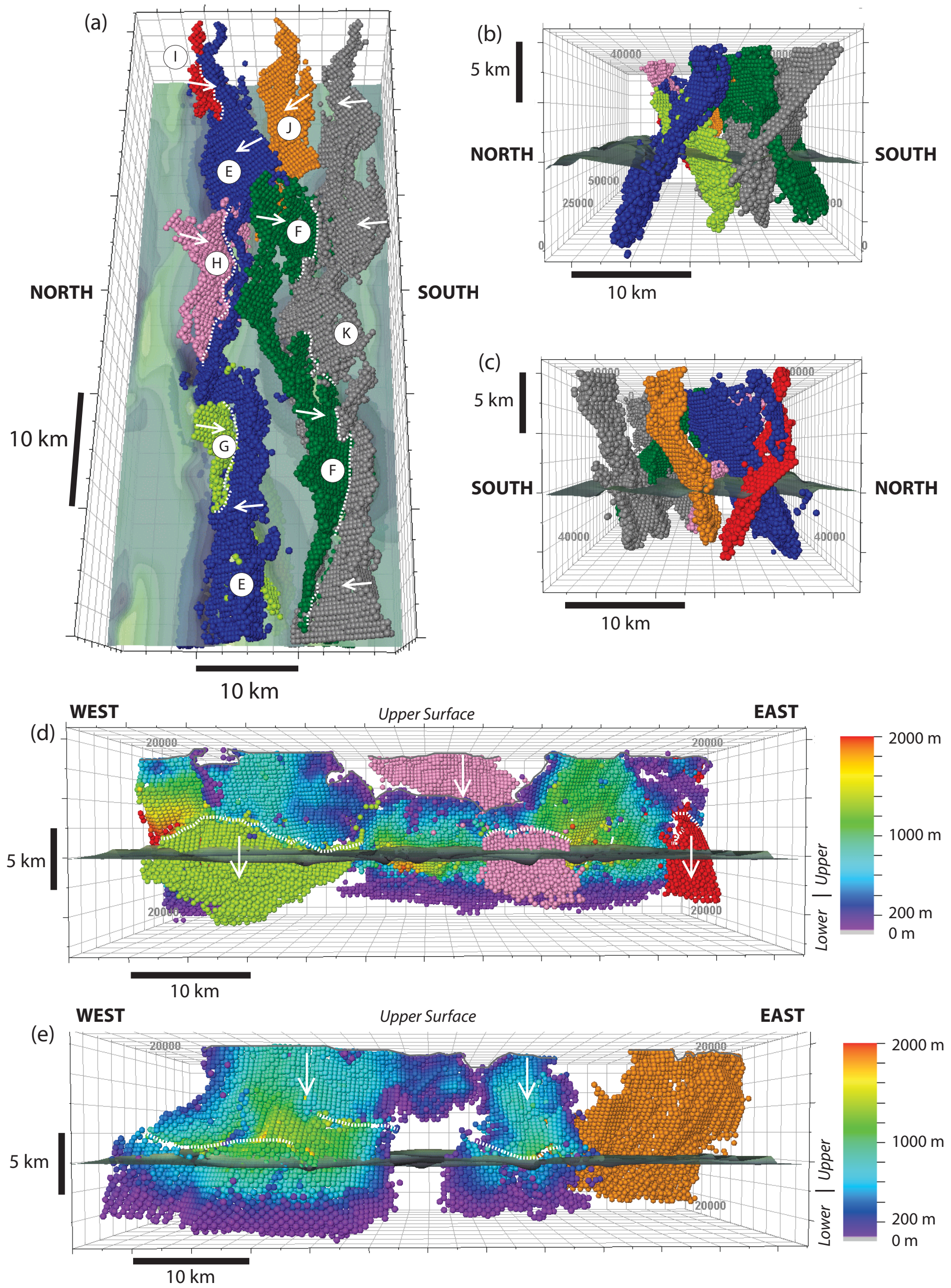

Fig. 11 
(a) Upper Surface (Horizon 102) NORTH

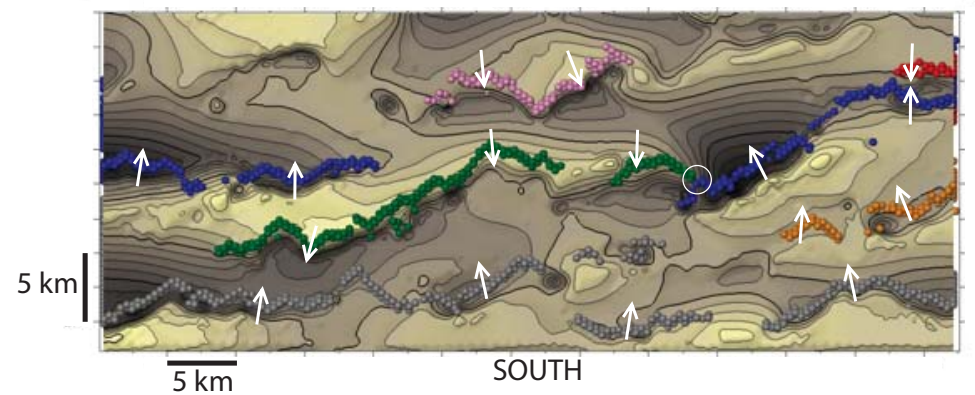

(b) Horizon 92 (-2.5 km) NORTH

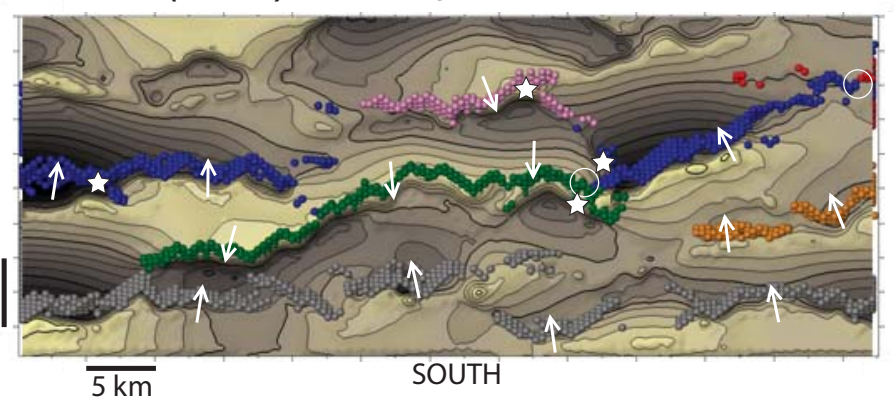

(c) Horizon $82(-5.1 \mathrm{~km})$

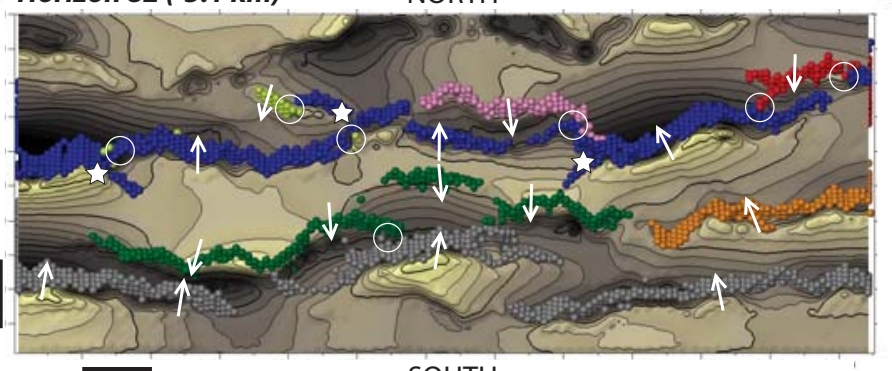

$\overline{5 \mathrm{~km}}$ (d) Horizon 72 (-7.8 km)

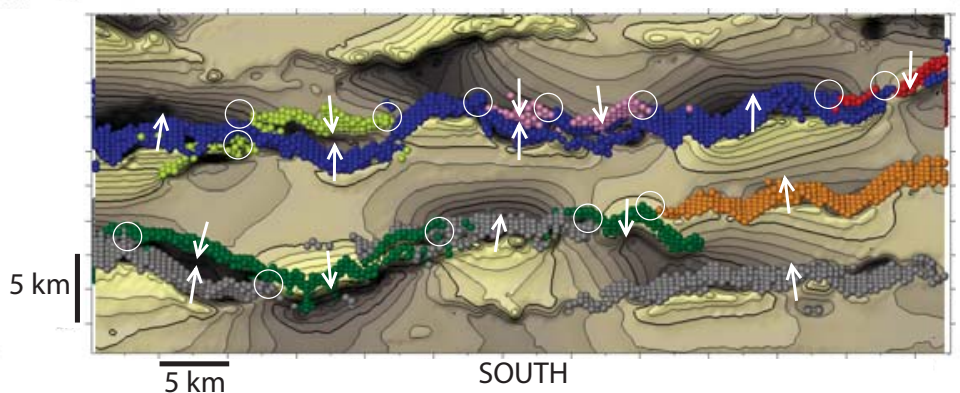

(e) Horizon 62 (-10.2 km)

NORTH

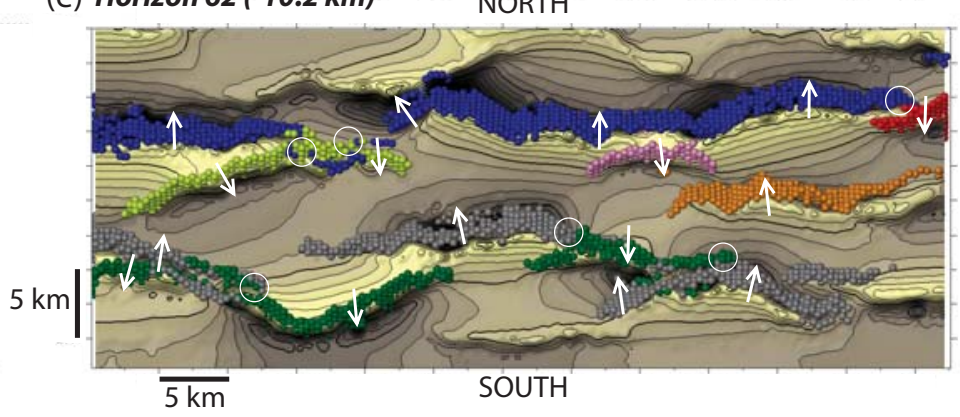

(f) Horizon $52(-12.1 \mathrm{~km})$

NORTH

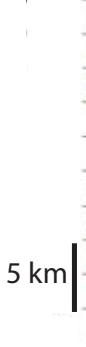$$
\text { (3) }
$$

RELIEF

$-+750 \mathrm{~m}$

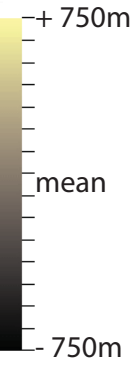

Fig. 12 


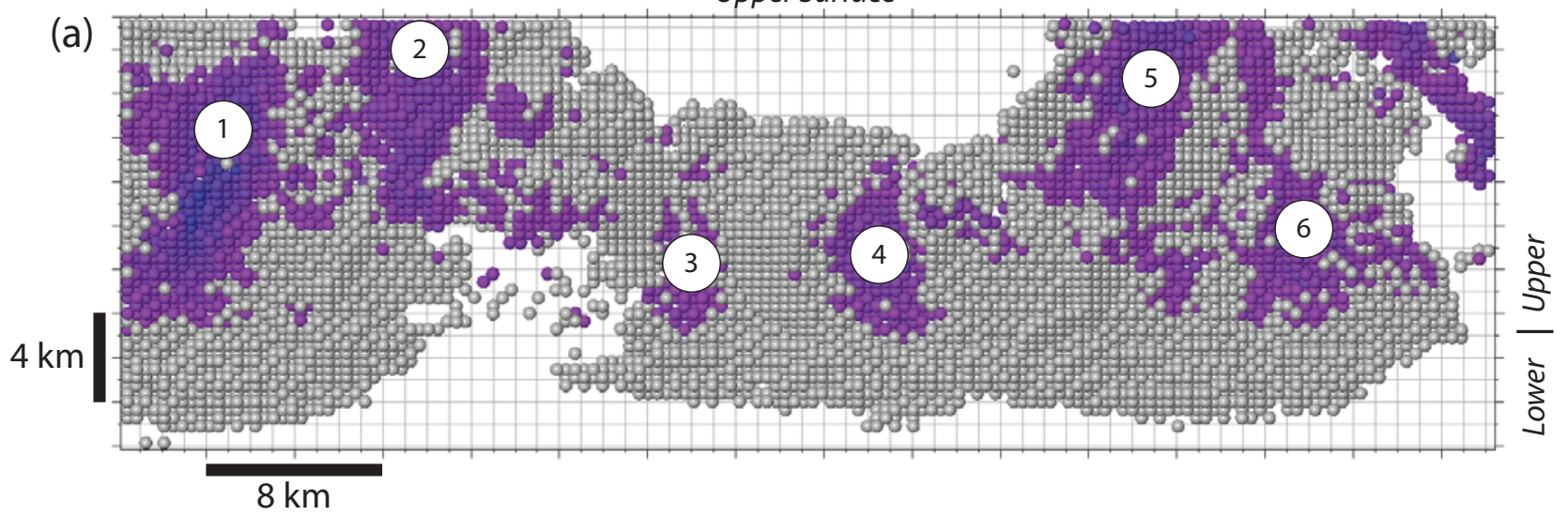

\section{$\frac{\bar{a}}{3}$}
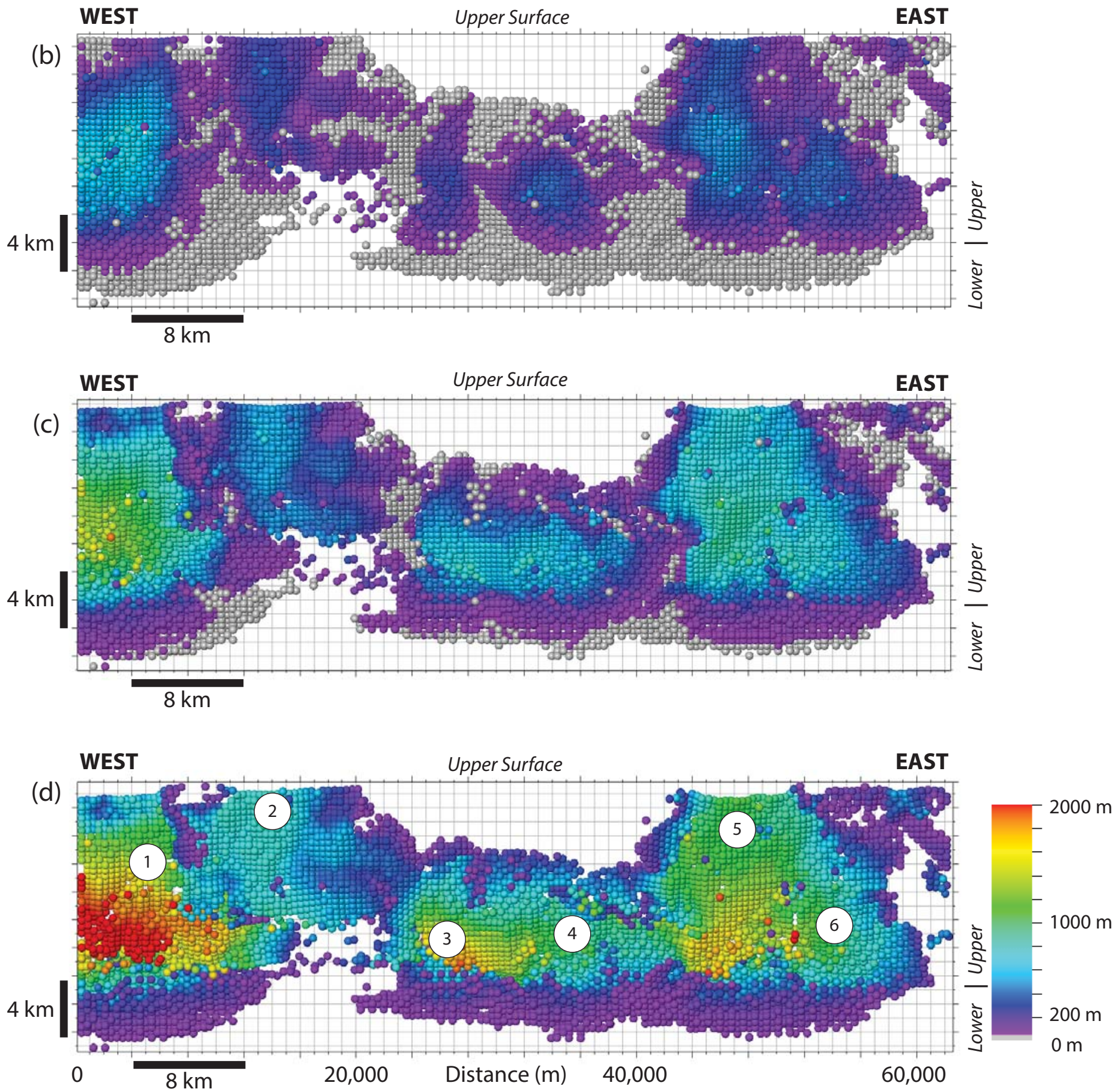

Fig. 13 


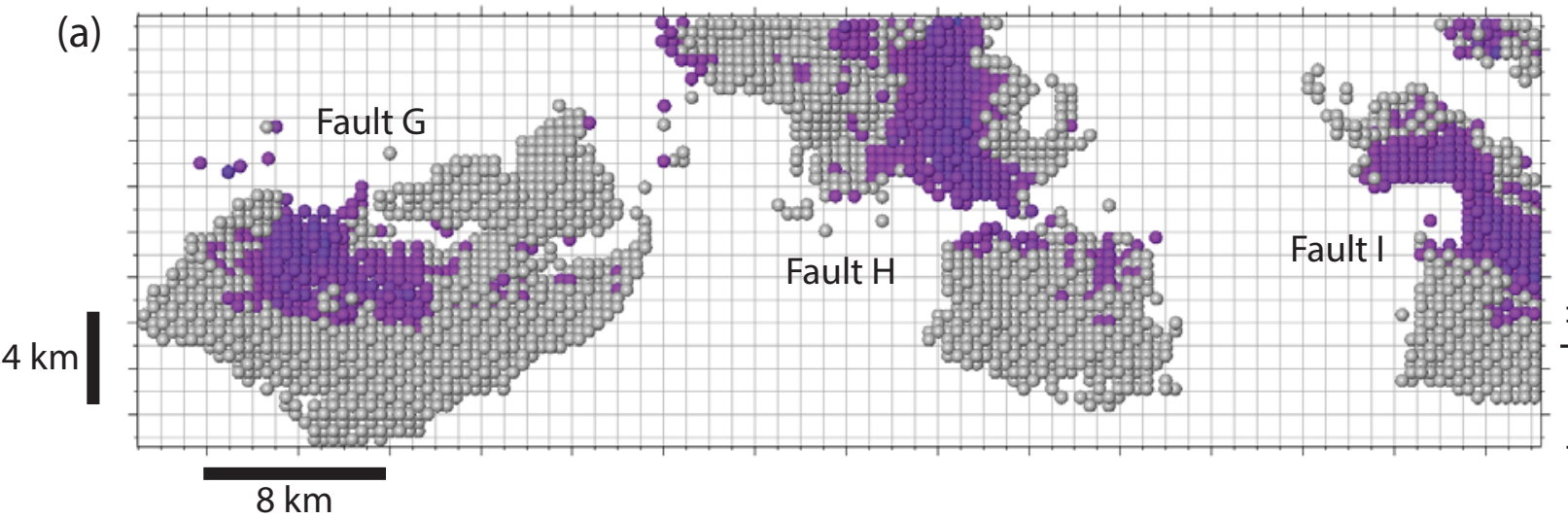

Upper Surface
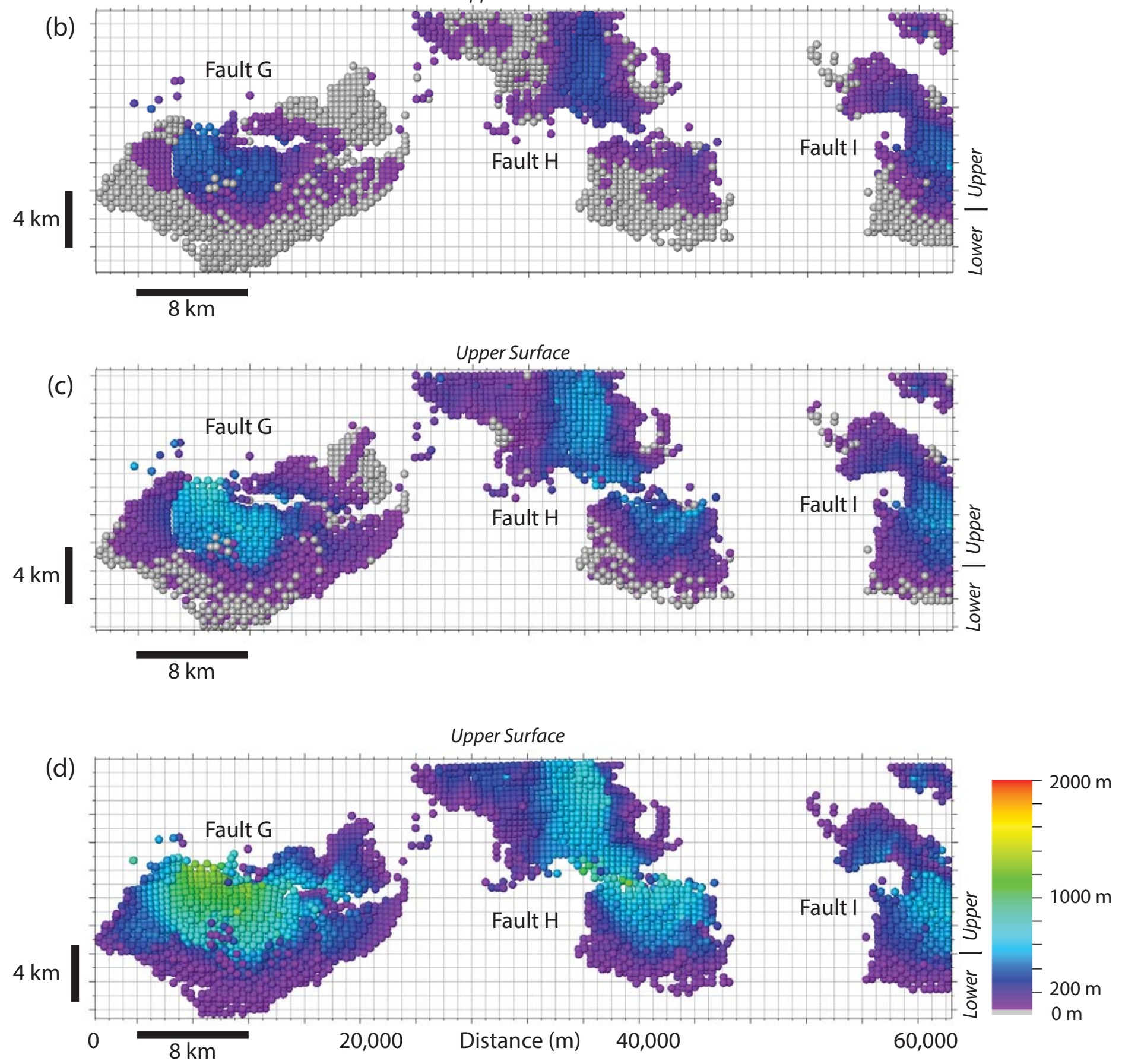

Fig. 14 


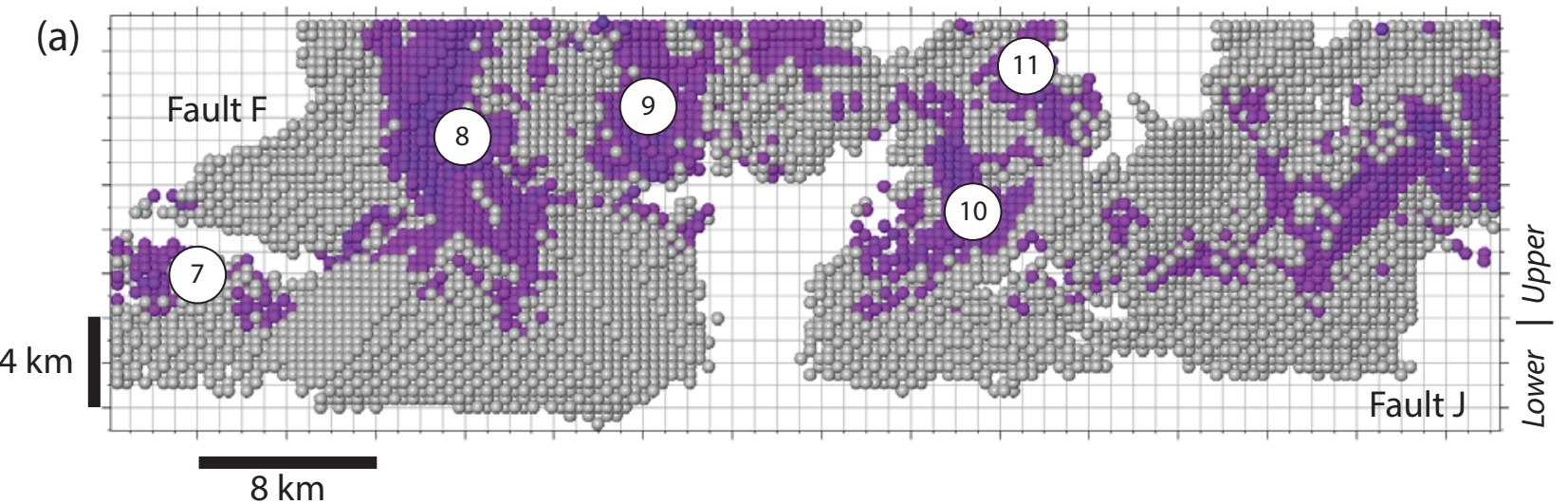

Upper Surface

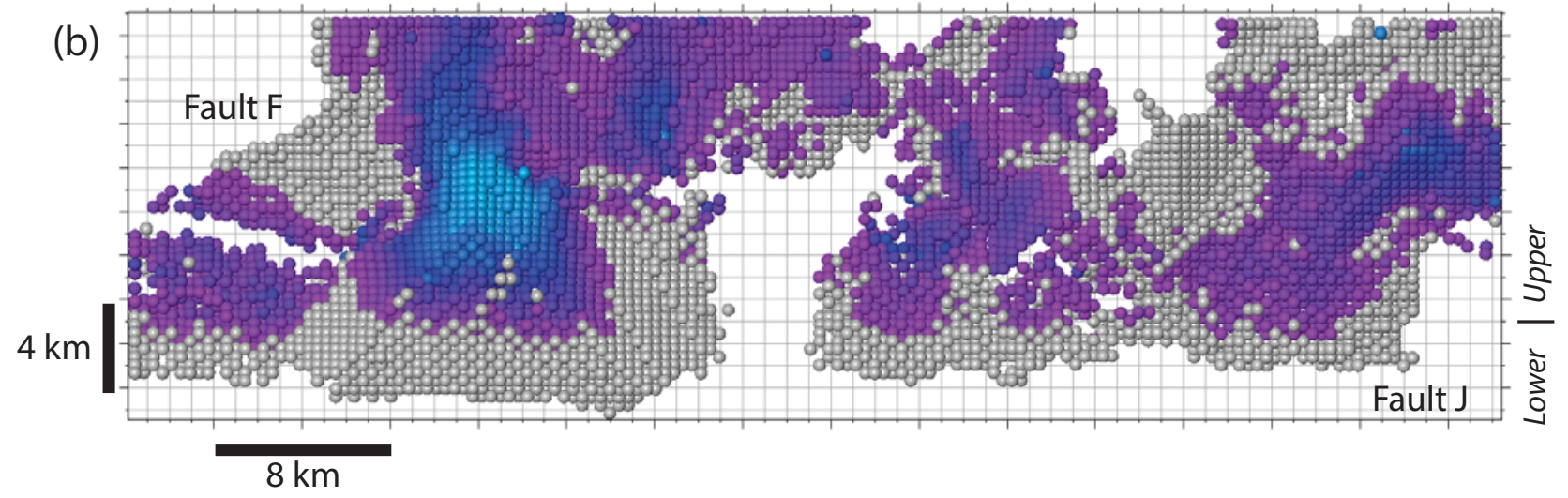

Upper Surface

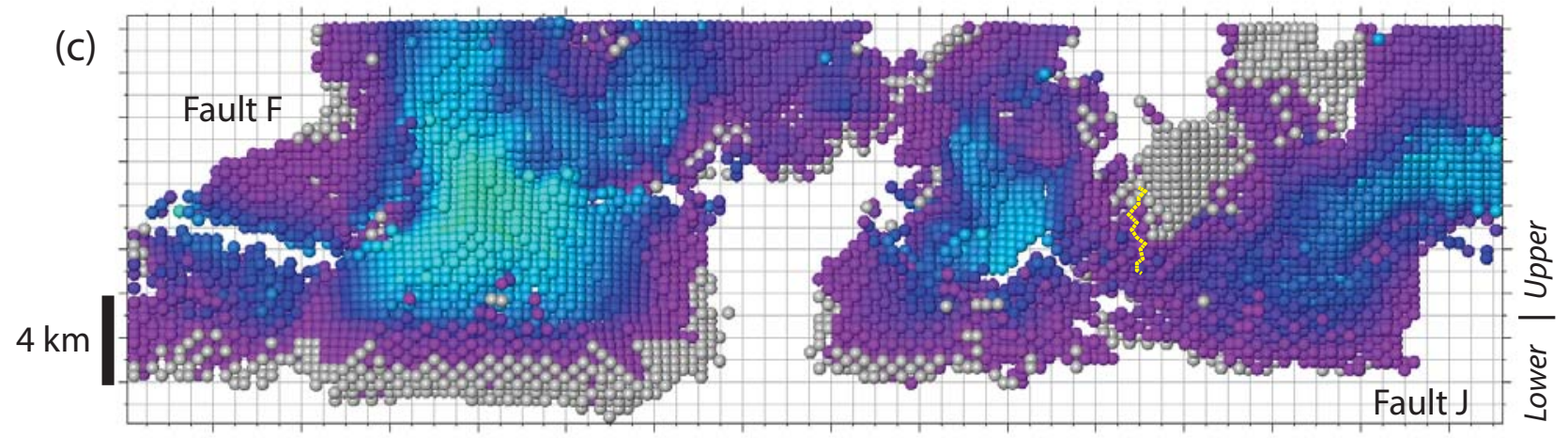

$8 \mathrm{~km}$

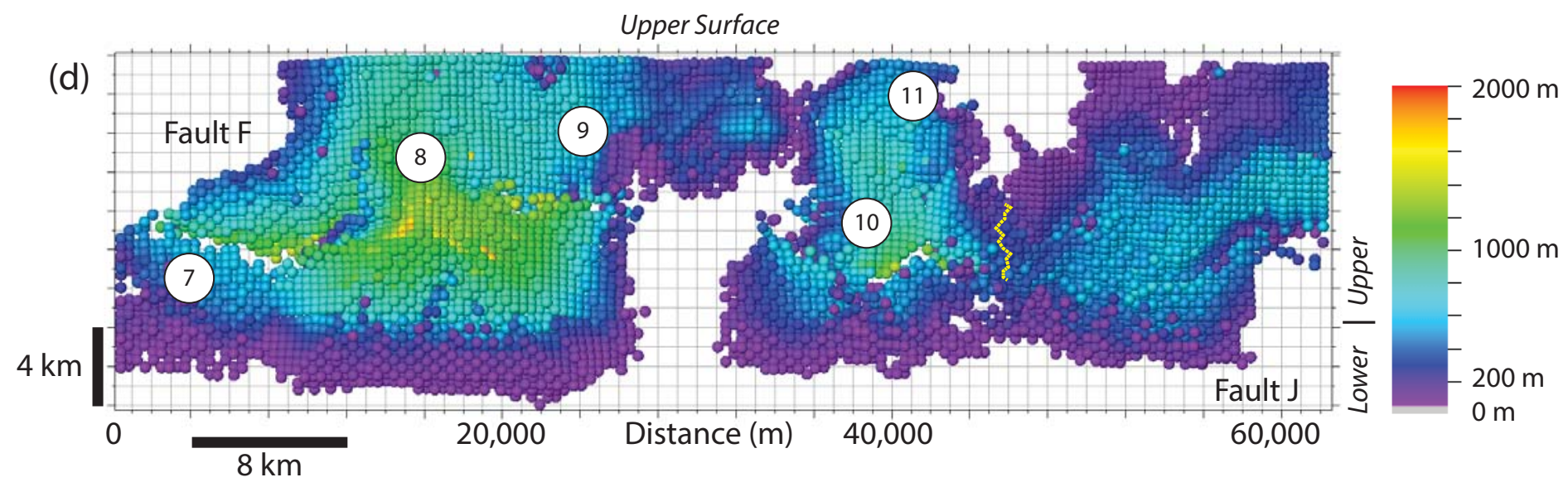

Fig. 15 


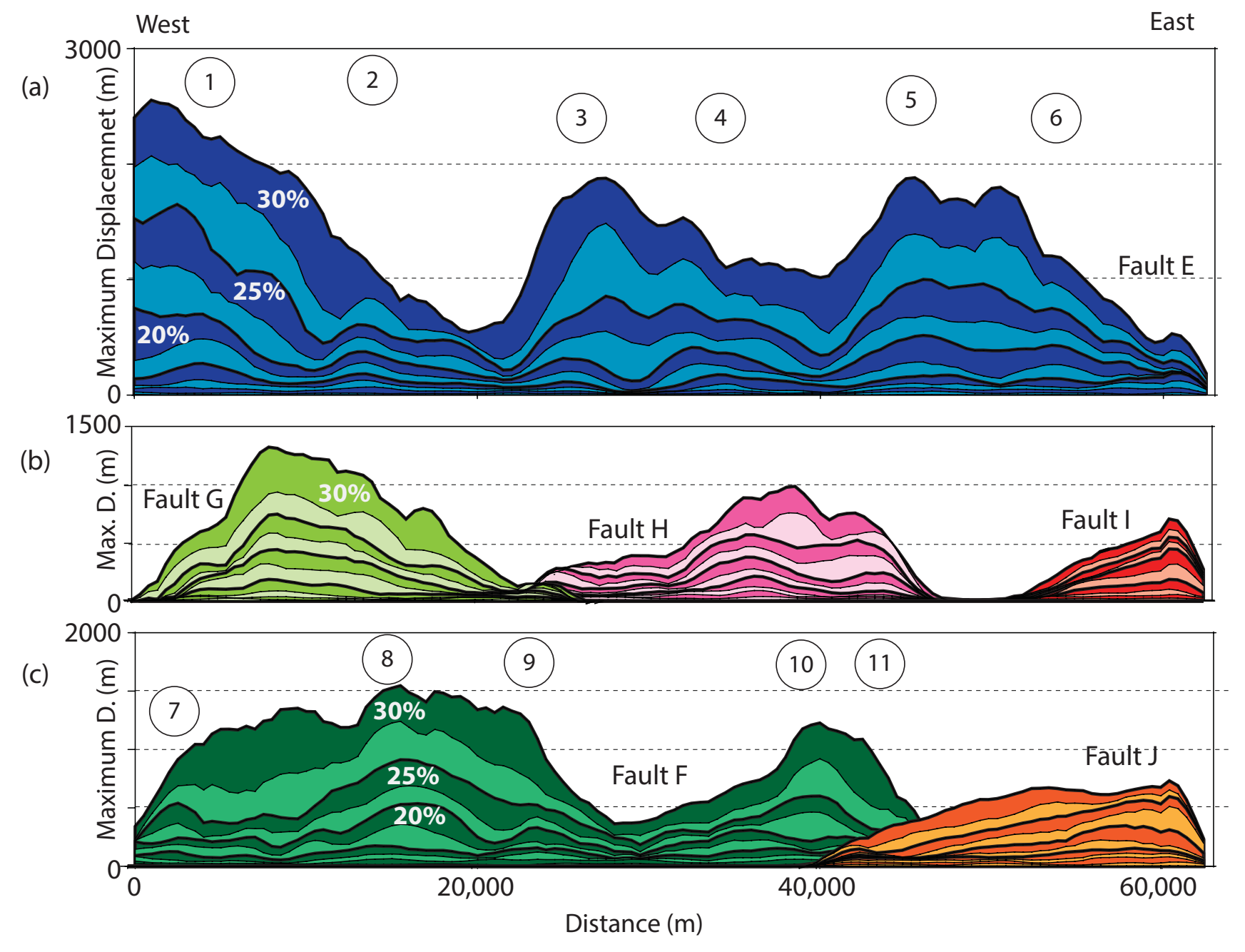

Fig. 16 


\section{Fault Network Evolution}

\section{Fault Segment Evolution}

\section{a) Stage 1: Nucleation $(<10 \%)$}

Large number of small faults initiate at varying depth within the crust orientated in a conjugate system
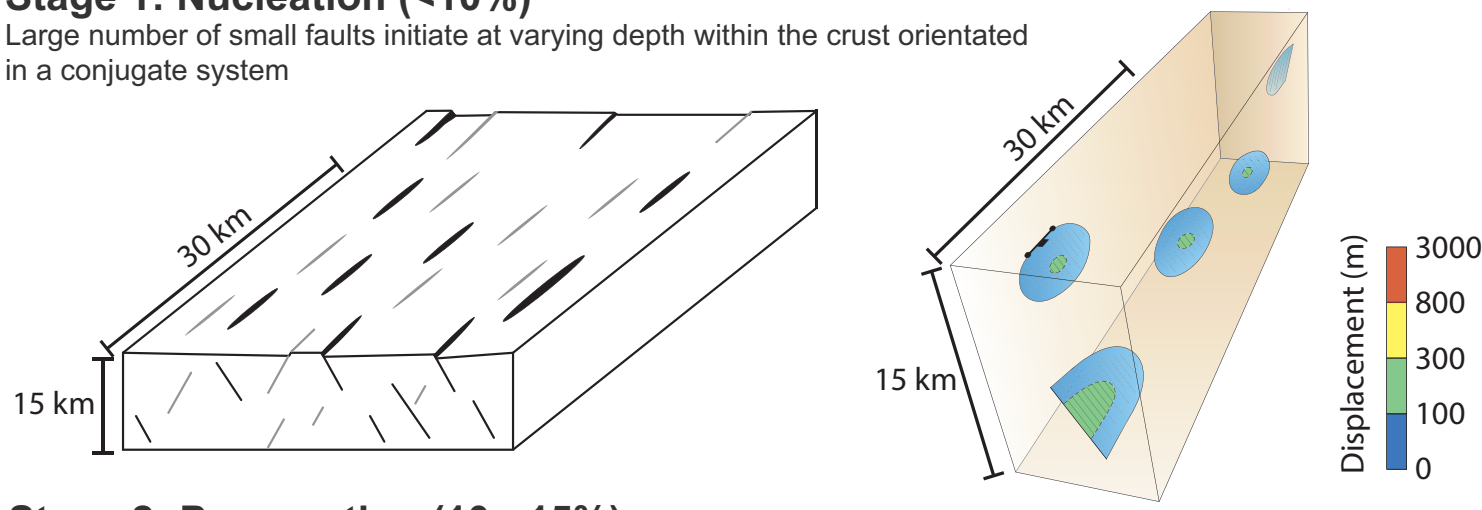

\section{b) Stage 2: Propagation (10 - 15\%)}

Isolated faults growing and interacting

dip domains fixing due to fault nucleation in opposing orientations
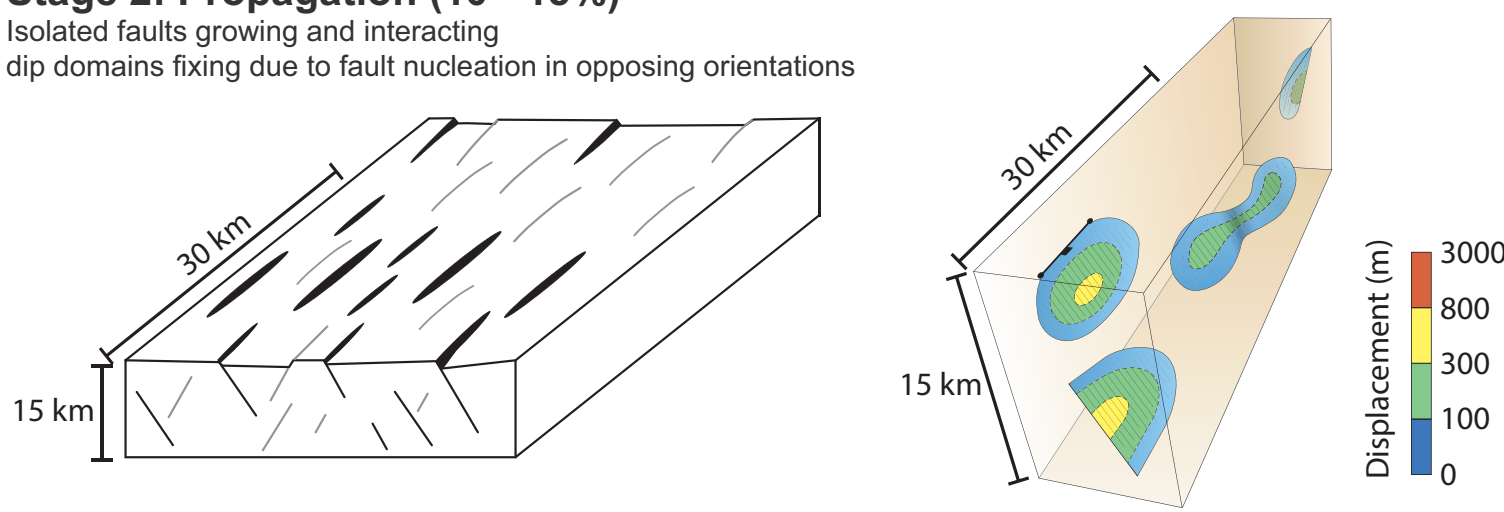

C) Stage 3: Domain fixing and linkage (15 - 20\%)

Grabens and tilted half-grabens form

Relays between similar and opposite dipping faults

Along-strike linkage through relay zones and initial breaching

Similar dipping faults coallesce down dip planes

$15 \mathrm{~km}$
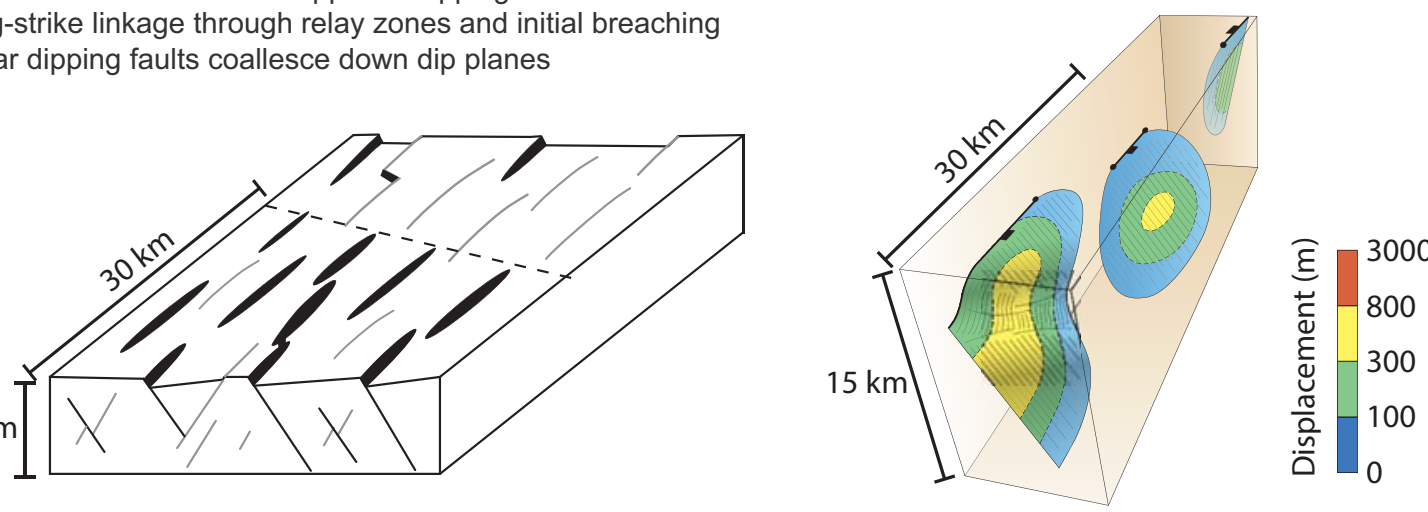

d) Stage 4: Localisation (20 - 30\%)

Extension localises onto larger faults

Some faults inactive in strain shadow of larger, more dominant neighbours

Along-strike linkage of dip-orientated faults through breached relays

Faults linked along strike and at depth
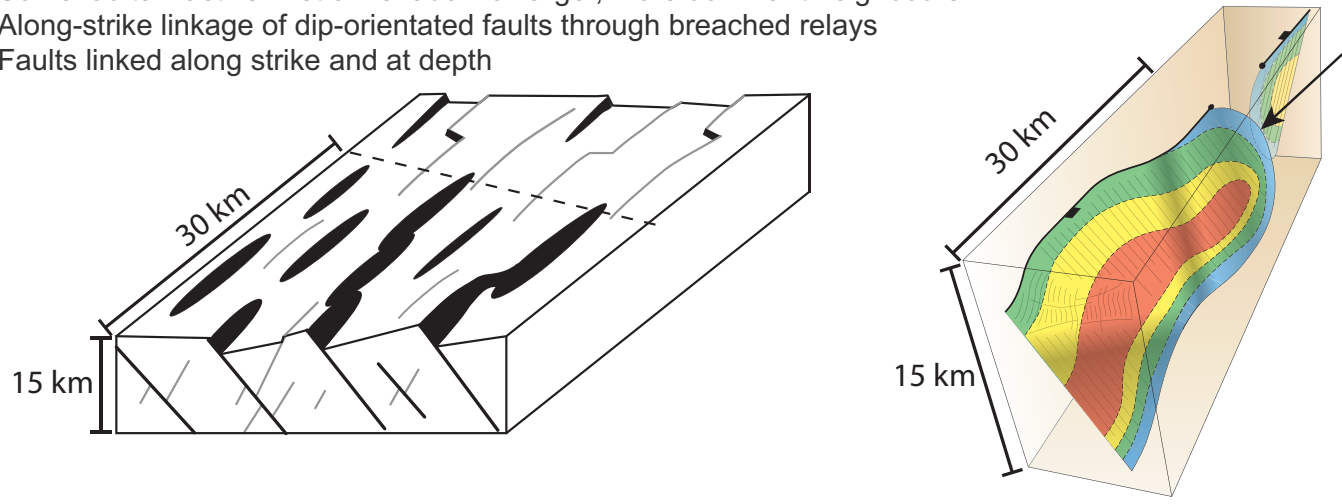

Oppositely dipping faults inhibit lateral propagation

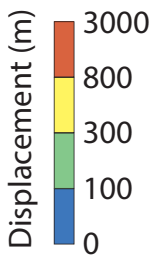

Fig. 17 


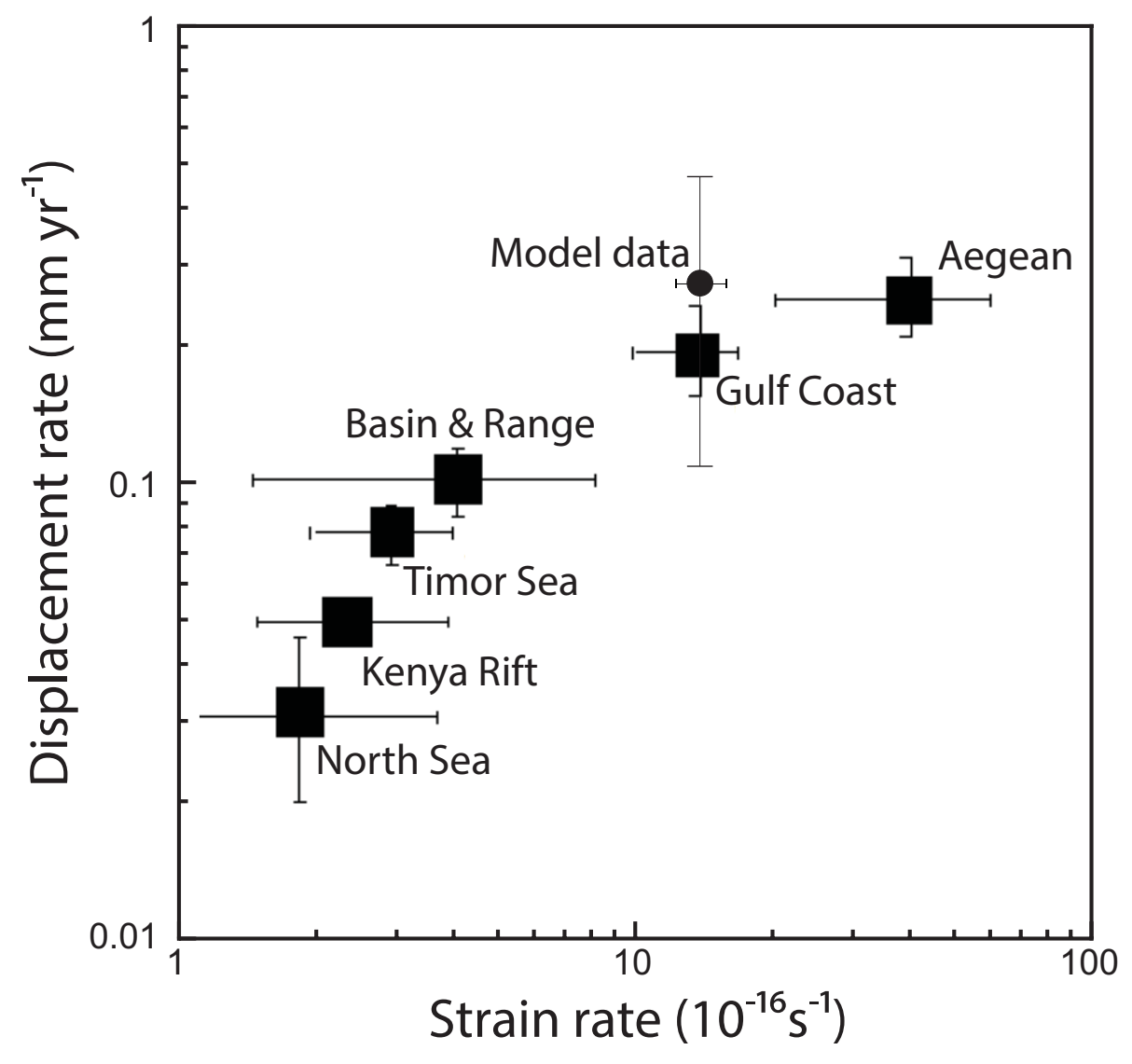

Fig. 18 